\title{
Experimental studies using minimum quantity cooling (MQC) with molybdenum disulfide and graphite-based microfluids in grinding of Inconel ${ }^{\circledR}$ alloy 718
}

\author{
Michał Wojtewicz ${ }^{1} \cdot \mathrm{Krzysztof} \mathrm{Nadolny}^{2} \cdot$ Wojciech Kapłonek ${ }^{3} \cdot \mathrm{Krzysztof} \mathrm{Rokosz}^{4} \cdot$ Dalibor Matýsek $^{5}$. \\ Miorița Ungureanu ${ }^{6}$
}

Received: 31 July 2018 / Accepted: 23 October 2018 / Published online: 6 November 2018

(C) The Author(s) 2018

\begin{abstract}
In the paper, the results of experimental studies related with determination of the influence of the supply of a grinding fluid (GF) doped with powdered graphite and $\mathrm{MoS}_{2}$ into the machining zone with the minimum quantity cooling (MQC) method on the course and results of the reciprocating internal cylindrical grinding of rings made from Inconel ${ }^{\circledR}$ alloy 718 have been presented. As a grinding fluid, water aerosols were used. The aerosols delivered the following into the grinding zone: water slurry $\mathrm{MoS}_{2}$ with a concentration of $30 \mathrm{~g} / \mathrm{dm}^{3}$, water slurry of graphite with a concentration of $30 \mathrm{~g} / \mathrm{dm}^{3}, 5 \%$ water solution of Syntilo RHS oil and pure demineralized water. The obtained results of carried out experiments showed that the most favorable conditions of grinding wheel operation were obtained when MQC-based delivering an aerosol of water slurry made from demineralized water doped with $\mathrm{MoS}_{2}$ and graphite with a minimum flow rate and when delivering an aerosol of 5\% water slurry of Syntilo RHS oil. It was proved that doping GF with powdered $\mathrm{MoS}_{2}$ and graphite, with delivery in the form of an aerosol with a minimum flow rate, has a substantial influence on the intensity of clogging grinding wheel active surface (GWAS). Additionally, it has been demonstrated that the solid grease $\mathrm{MoS}_{2}$ and graphite particles reached the area of contact of the GWAS and the machined surface effectively, actively influencing its tribological conditions of the grinding process.
\end{abstract}

Keywords Minimum quantity cooling $\cdot$ Flood cooling $\cdot$ Grinding process $\cdot$ Surface roughness $\cdot$ Inconel ${ }^{\circledR}$ alloy 718

Krzysztof Nadolny

krzysztof.nadolny@tu.koszalin.pl

Michał Wojtewicz

michal.wojtewicz@tu.koszalin.pl

Wojciech Kapłonek

wojciech.kaplonek@tu.koszalin.pl

Krzysztof Rokosz

krzysztof.rokosz@tu.koszalin.pl

Dalibor Matýsek

dalibor.matysek@vsb.cz

Miorița Ungureanu

miorita.ungureanu@cunbm.utcluj.ro

1 Subject Group of Applied Chemistry, Department of Production Engineering, Faculty of Mechanical Engineering, Koszalin University of Technology, Racławicka 15-17,

75-620 Koszalin, Poland
2 Department of Production Engineering, Faculty of Mechanical Engineering, Koszalin University of Technology, Racławicka 15-17, 75-620 Koszalin, Poland

3 Subject Group of Metrology and Quality, Department of Production Engineering, Faculty of Mechanical Engineering, Koszalin University of Technology, Racławicka 15-17,

75-620 Koszalin, Poland

4 Subject Group of Bioengineering and Surface Electrochemistry, Faculty of Mechanical Engineering, Koszalin University of Technology, Racławicka 15-17, 75-620 Koszalin, Poland

5 Faculty of Mining and Geology, Technical University of Ostrava, 17. listopadu 15/2172, Poruba, 70833 Ostrava, Czech Republic

6 Department of Engineering and Technology Management, Technical University of Cluj Napoca, North University Center of Baia Mare, Dr. Victor Babes 62A, 430083 Baia Mare, Romania 


\section{Nomenclature}

EDS Energy-dispersive X-ray spectroscopy

GF Grinding fluid

GWAS Grinding wheel active surface

MQC Minimum quantity cooling

MQL Minimum quantity lubrication

SDD Silicon drift detector

SEM Scanning electron microscopy

SQL Small quantity lubrication

$a_{a} \quad$ Axial engagement, $\mathrm{mm}$

$a_{d} \quad$ Dressing allowance, $\mathrm{mm}$

$a_{e} \quad$ Working engagement (machining allowance), $\mathrm{mm}$

$a_{e}$ tot Total working engagement (machining allowance), $\mathrm{mm}$

$a_{f} \quad$ Feed engagement, $\mathrm{mm}$

$b_{s} \quad$ Width of the grinding wheel measured parallel to the wheel axis, $\mathrm{mm}$

$b_{w} \quad$ Workpiece width, mm

$d_{s} \quad$ Grinding wheel outer diameter, $\mathrm{mm}$

$d_{w} \quad$ Workpiece diameter, $\mathrm{mm}$

$e \quad$ Specific sliding grinding energy, $\mathrm{J} / \mathrm{mm}^{3}$ $h_{s} \quad$ Grinding wheel inner diameter, $\mathrm{mm}$

$i_{d} \quad$ Number of dressing passes

$n_{s} \quad$ Grinding wheel rotational speed, $\min ^{-1}$

$n_{s d} \quad$ Grinding wheel rotational speed while dressing, $\min ^{-1}$

$n_{w} \quad$ Workpiece rotational speed, $\min ^{-1}$

$t_{g} \quad$ Grinding time, s

$v_{f a} \quad$ Axial table feed speed while grinding, $\mathrm{mm} \cdot \mathrm{s}^{-1}$

$v_{f d} \quad$ Axial table feed speed while dressing, $\mathrm{mm} \cdot \mathrm{s}^{-1}$

$v_{f r} \quad$ Radial table feed speed while grinding, $\mathrm{mm} \cdot \mathrm{min}^{-1}$

$v_{s} \quad$ Grinding wheel peripheral speed, $\mathrm{m} \cdot \mathrm{s}^{-1}$

$v_{w} \quad$ Workpiece peripheral speed, $\mathrm{m} \cdot \mathrm{s}^{-1}$

At Atomic percentage, $\%$

$G \quad$ Grinding index, $\mathrm{mm}^{3} / \mathrm{mm}^{3}$

$Q_{d} \quad$ Diamond dresser mass, kt

$Q_{\mathrm{GF}} \quad$ Grinding fluid flow rate, $\mathrm{L} \cdot \mathrm{min}^{-1}$

$\mathrm{Sa} \quad$ Arithmetic mean deviation of the surface, $\mu \mathrm{m}$

Sp Maximum height of peaks, $\mu \mathrm{m}$

St Total height of the surface, $\mu \mathrm{m}$

Sv $\quad$ Maximum height of valleys, $\mu \mathrm{m}$

$S d q \quad$ Root mean square gradient of the surface, $\mu \mathrm{m} / \mu \mathrm{m}$
Fig. 1 Minimal atomizer ZMINMS (Sommer-Technik GmbH, Straubenhardt, Germany) equipped with flexible metal hose $(l=232 \mathrm{~mm})$ used in the experimental studies. a General view of the device. $\mathbf{b}$ Device during internal cylindrical grinding process of Inconel ${ }^{\mathbb{R}}$ alloy 718

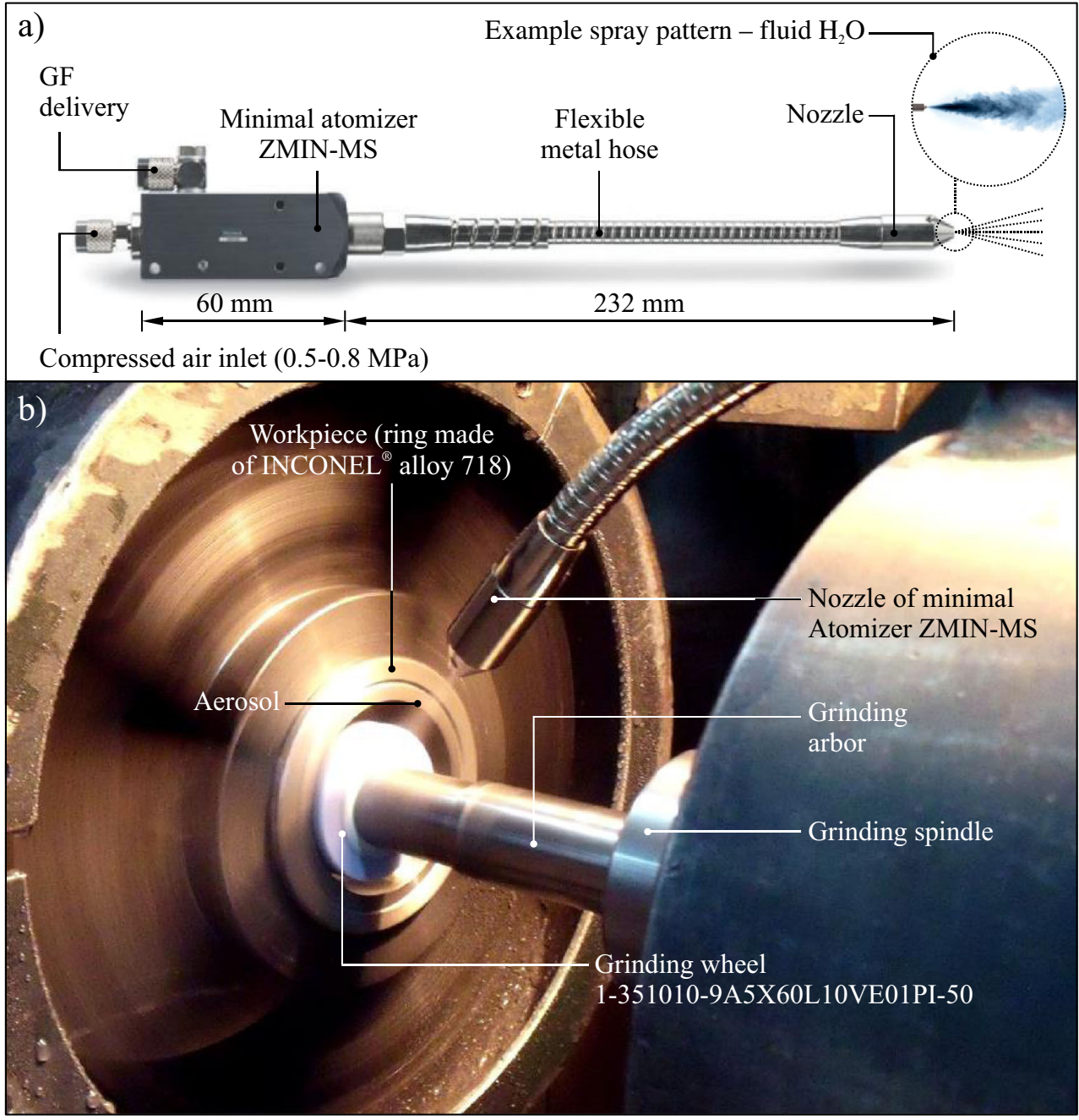


Table 1 Characteristics of grinding conditions

\begin{tabular}{|c|c|c|}
\hline Grinding process & \multicolumn{2}{|l|}{ Reciprocal peripheral internal cylindrical grinding } \\
\hline Grinding machine & \multicolumn{2}{|l|}{ Universal grinding machine: RUP 28P by Tarnów Mechanical Works SA, Tarnów, Poland } \\
\hline Grinding wheel & \multicolumn{2}{|l|}{$1-35 \times 10 \times 10-9$ A 5 X60L10VE01PI-50 } \\
\hline $\begin{array}{l}\text { Grinding wheel } \\
\text { dressing } \\
\text { parameters }\end{array}$ & \multicolumn{2}{|l|}{$\begin{array}{l}\text { Dresser: single grain diamond dresser with mass: } Q_{d}=1.25 \mathrm{kt} \text {, } \\
\text { Grinding wheel rotational speed while dressing: } n_{s d}=10,000 \mathrm{rpm} \\
\text { Dressing allowance: } a_{d}=0.0125 \mathrm{~mm} \\
\text { Axial table feed speed while dressing: } v_{f d}=10 \mathrm{~mm} / \mathrm{s} \\
\text { Number of dressing passes: } i_{d}=6\end{array}$} \\
\hline $\begin{array}{l}\text { Grinding } \\
\text { parameters }\end{array}$ & \multicolumn{2}{|l|}{$\begin{array}{l}\text { Grinding wheel peripheral speed: } v_{s}=45 \mathrm{~m} / \mathrm{s} \\
\text { Axial table feed speed: } v_{f a}=10 \mathrm{~mm} / \mathrm{s} \\
\text { Working engagement (machining allowance): } a_{e}=0.01 \mathrm{~mm} \\
\text { Total working engagement (machining allowance): } a_{e} \text { tot }=0.75 \mathrm{~mm} \\
\text { Workpiece peripheral speed: } v_{w}=0.56 \mathrm{~m} / \mathrm{s} \\
\text { Total grinding time } t_{g} \text { tot }=900 \mathrm{~s}\end{array}$} \\
\hline Workpieces & \multicolumn{2}{|c|}{ Internal cylindrical surface of rings, made of INCONEL ${ }^{\circledR}$ alloy 718, internal diameter: $d_{\mathrm{w}}=40 \mathrm{~mm}$, width: $b_{w}=20 \mathrm{~mm}$} \\
\hline GF delivery method & Water aerosol delivered by a single spray nozzle & $\begin{array}{l}\text { GF delivered using flood method } \\
\text { (reference method) }\end{array}$ \\
\hline $\begin{array}{l}\text { GF working } \\
\text { pressure }\end{array}$ & Supply air pressure: $0.8 \mathrm{MPa}$ & GF working pressure: $0.12 \mathrm{MPa}$ \\
\hline GF type & $\begin{array}{l}\text { 1. Water slurry (demineralized water) } \mathrm{MoS}_{2} \text { with a concentration of } 30 \mathrm{~g} / \mathrm{dm}^{3} \text {. } \\
\text { 2. Water slurry (demineralized water) of graphite with a concentration of } 30 \mathrm{~g} / \mathrm{dm}^{3} \text {. } \\
\text { 3. } 5 \% \text { water solution of Syntilo RHS oil (Castrol Ltd., Liverpool, Great Britain) } \\
\text { (reference GF-standard emulsion delivered with a minimum flow rate). } \\
\text { 4. Pure demineralized water } \\
\text { (reference GF-non-doped with powdered graphite or } \mathrm{MoS}_{2} \text { ). }\end{array}$ & $\begin{array}{l}5 \% \text { water solution of Syntilo RHS oil } \\
\text { (Castrol Ltd., Liverpool, Great Britain) }\end{array}$ \\
\hline GF flow rate & $Q_{G F}=1080 \mathrm{ml} / \mathrm{h}$ & $Q_{G F}=2.71 / \mathrm{min}$ \\
\hline
\end{tabular}

$S d r \quad$ Developed interfacial area ratio, $\%$

$S d s \quad$ Density of summits of the surface, $\mathrm{pks} / \mathrm{mm}^{-2}$

Sku Kurtosis of height distribution, -

Ssc Mean summit curvature, $1 / \mu \mathrm{m}$

Ssk Skewness of height distribution, -

Std Texture direction of the surface, ${ }^{\circ}$

Str Texture aspect ratio of the surface, -

$\mathrm{Ua} \quad$ Accelerating voltage (SEM), $\mathrm{kV}$

$V_{b} \quad$ Volume of bond in the grinding wheel, \%

$V_{g} \quad$ Volume of abrasive grains in the grinding wheel, $\%$

$V_{p} \quad$ Volume of pores in the grinding wheel, $\%$

$V_{s} \quad$ Volume of grinding wheel wear, $\mathrm{mm}^{3}$

$V_{w} \quad$ Volume of material removed, $\mathrm{mm}^{3}$

$\begin{array}{ll}\text { WD } & \text { Working distance, } \mathrm{mm} \\ \mathrm{Wt} & \text { Weight percentage, } \% \\ \mu & \text { Coefficient of sliding friction, }- \\ \Delta P_{a v} & \text { Average grinding power increase, } \mathrm{W} \\ \Delta P_{l} & \text { Limited value of grinding power increase, } \mathrm{W}\end{array}$

\section{Introduction}

Advanced engineering materials known as superalloys, such as Inconel ${ }^{\circledR}[1-5]$, Incoloy® $[6,7]$, Nimonic ${ }^{\circledR}[8,9]$, and Hastelloy $^{\circledR}[10,11]$ and various types of titanium alloys $[12$, 13] lay down new requirements for abrasive machining

Table 2 Characteristics of samples used in the experimental studies

\begin{tabular}{|c|c|c|c|c|c|}
\hline No. & $\begin{array}{l}\text { Sample } \\
\text { designation }\end{array}$ & $\begin{array}{l}\text { Type of } \\
\text { cooling }\end{array}$ & Type of liquid & Components & $\begin{array}{l}\text { Grinding fluid } \\
\text { flow rate }\end{array}$ \\
\hline 1. & MQC-M & MQC & $\begin{array}{l}\text { Aerosol of } \\
\text { suspension }\end{array}$ & $\begin{array}{l}\text { Compressed air + suspension of demineralized water doped with molybdenum } \\
\text { disulfide } \mathrm{MoS}_{2} \text { (concentration } 30 \mathrm{~g} / \mathrm{dm}^{3} \text { ) }\end{array}$ & $Q_{G F}=1080 \mathrm{l} / \mathrm{h}$ \\
\hline 2. & MQC-G & MQC & $\begin{array}{l}\text { Aerosol of } \\
\text { suspension }\end{array}$ & $\begin{array}{l}\text { Compressed air }+ \text { suspension of demineralized water doped with graphite } \\
\left(\text { concentration } 30 \mathrm{~g} / \mathrm{dm}^{3} \text { ) }\right.\end{array}$ & $Q_{G F}=1080 \mathrm{l} / \mathrm{h}$ \\
\hline 3. & MQC-E & MQC & Aerosol of emulsion & $\begin{array}{l}\text { Compressed air }+5 \% \text { water solution of Sintilo RHS oil } \\
\text { (Castrol, Liverpool, Great Britain) }\end{array}$ & $Q_{G F}=1080 \mathrm{l} / \mathrm{h}$ \\
\hline 4. & MQC-W & MQC & $\begin{array}{l}\text { Aerosol of } \\
\text { demineralized } \\
\text { water }\end{array}$ & Compressed air + demineralized water & $Q_{G F}=1080 \mathrm{l} / \mathrm{h}$ \\
\hline 5. & FM-REF & FM & Emulsion & $5 \%$ water solution of Sintilo RHS oil (Castrol, Liverpool, Great Britain) & $Q_{G F}=2.71 / \mathrm{min}$ \\
\hline
\end{tabular}




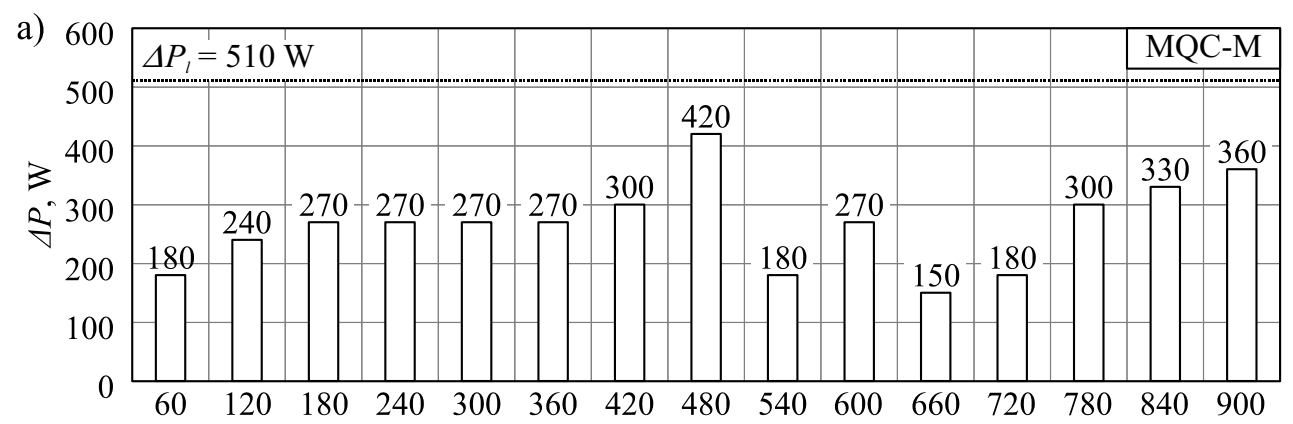

b)

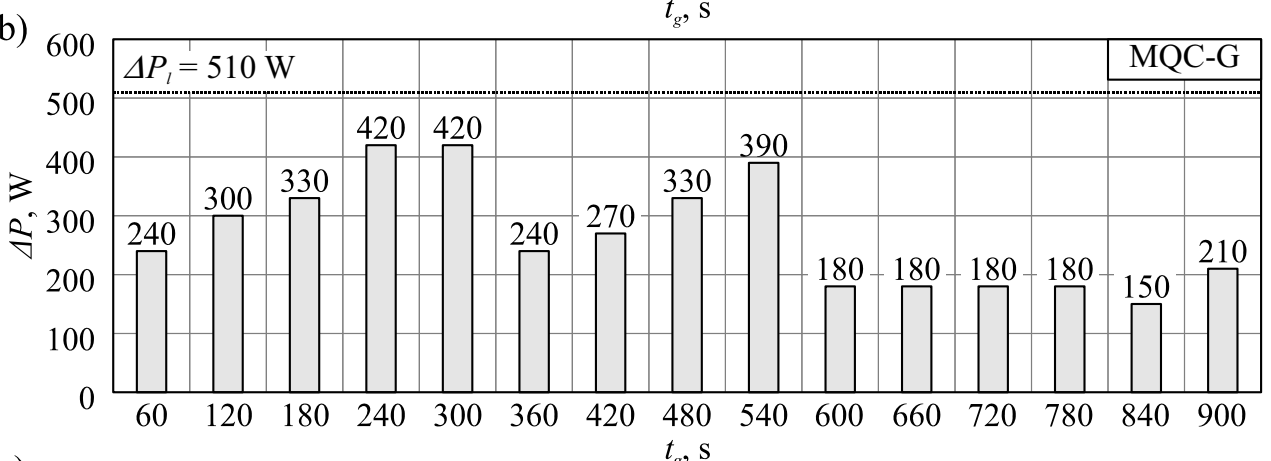

Grinding

parameters:

$v_{s}=45 \mathrm{~m} / \mathrm{s}$

$v_{w}=0.56 \mathrm{~m} / \mathrm{s}$

$v_{f a}=10 \mathrm{~mm} / \mathrm{s}$

$a_{e}=0.01 \mathrm{~mm}$

Grinding

wheel:

$1-35 \times 10 \times 10-$

$9 \mathrm{~A} 5 \mathrm{X} 60 \mathrm{~L} 10$

VE01PI-50

Workpiece:

ring made of

INCONEL $^{\circledR}$

alloy 718
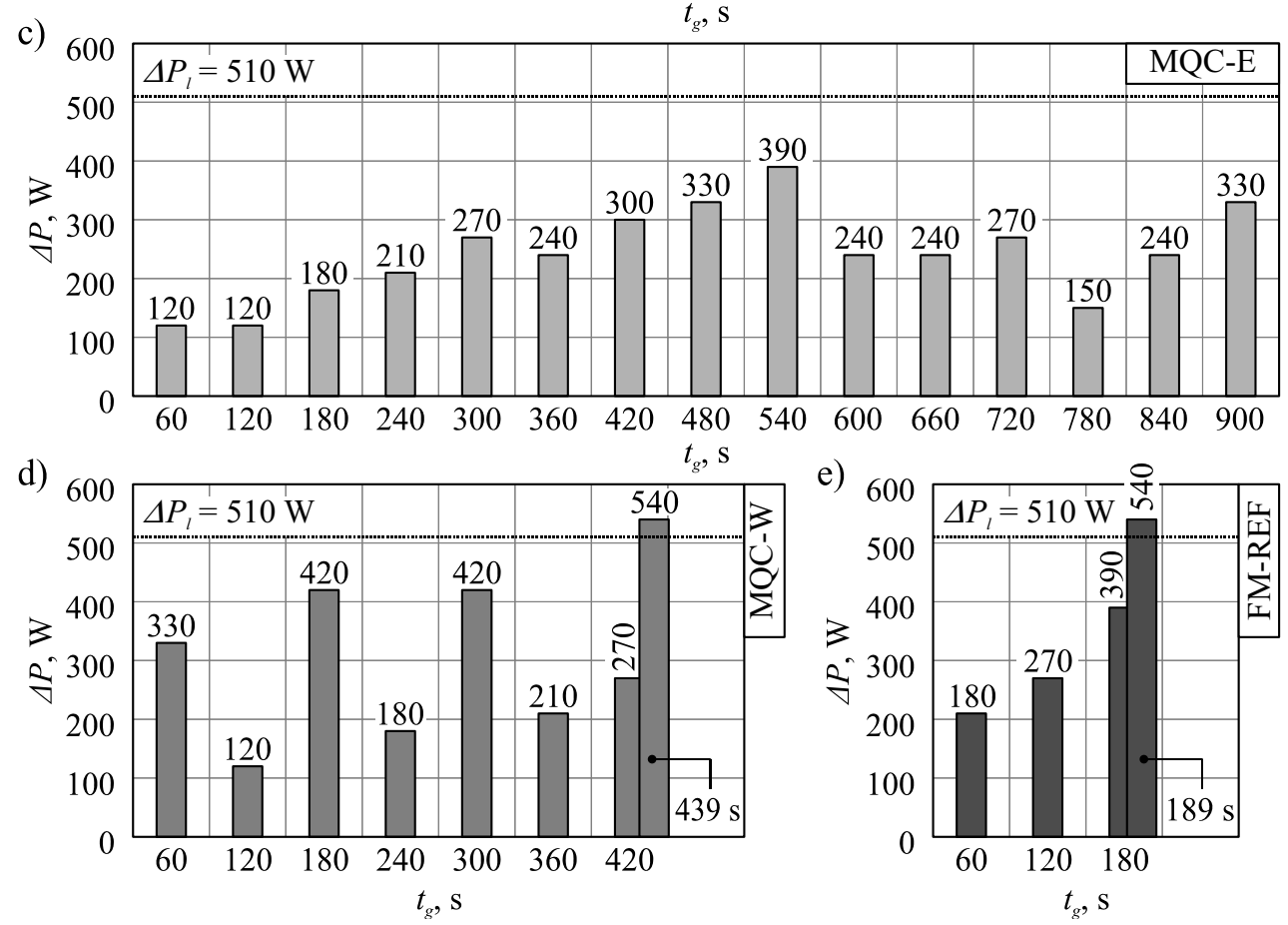

Fig. 2 Changes in grinding power increase $\Delta P$ during time $t_{g}$ of internal cylindrical grinding of Inconel ${ }^{\mathbb{R}}$ alloy 718 for the five considered variants of cooling and lubrication conditions. a MQC-M. b MQC-G. c MQC-E. d MQC-W. e FM-REF

processes. These alloys, characterized by their poor grindability, belong to the hard-to-cut materials family.

Grinding is a high-energy process. During the material removal process, the majority of energy is converted into heat. Chips absorb $75 \%$ of the heat, while $18 \%$ of the energy is converted into heat in the contact zone of the grinding wheel and the chip. The rest of the heat is absorbed by the workpiece or converted into heat in the contact zone of the grinding wheel and the workpiece. A high grinding temperature at the grinding principal point can accelerate the abrasive tool wear, as well as cause other disadvantages in its external and internal structure as reported by Rowe [14] as well as by Shen and Shih [15]. This disadvantages may include:

- grain growth, precipitation, softening;

- phase transformations leading to re-hardening;

- thermal expansion and contraction, cracking and tensile residual stresses; 
a)

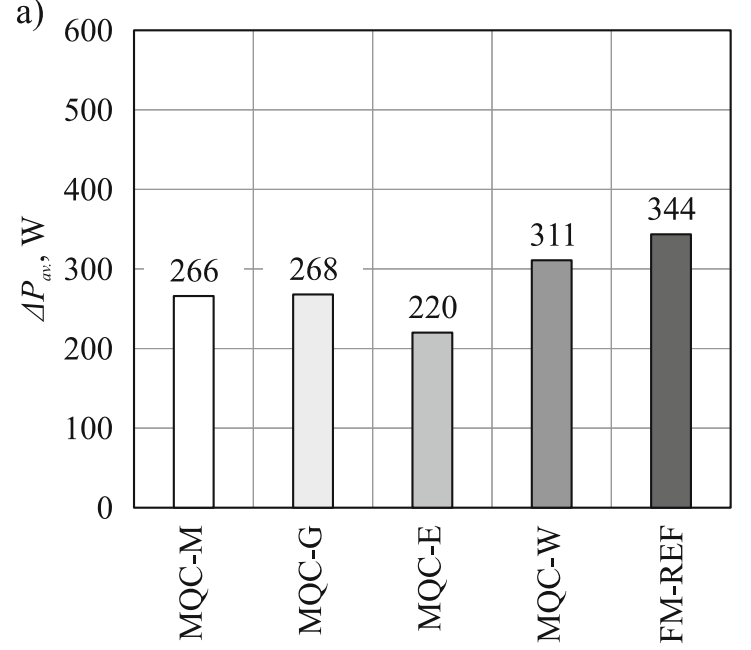

c)

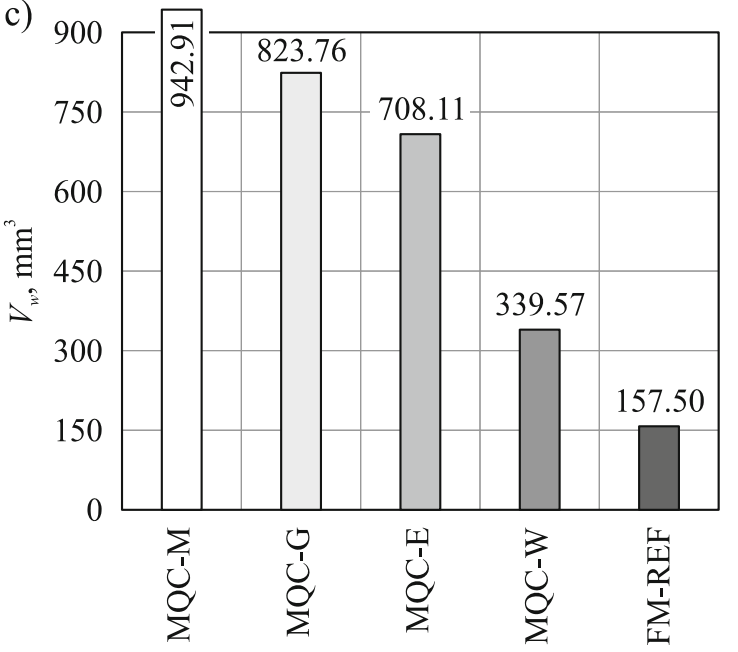

Fig. 3 Values of parameters describing the efficiency of the internal cylindrical grinding of Inconel ${ }^{\circledR}$ alloy 718 for the five considered variants of cooling and lubrication conditions. a Average increase in

- chemical reactions leading to burn marks;

- adhesion wear on the surface of the grinding wheel (wheel loading).

For the abovementioned reasons, unfavourable temperature effects must be limited and, therefore, a significant issue covering the grinding process is the exploration of new methods of their reduction.

Thermal damage can be usually avoided and overcome by using different types of grinding fluids (GFs). The most common are oil-in-water emulsions, neat mineral oils and neat synthetic oils. Inertial gases or solid lubricants are also being increasingly used [14]. Moreover, Rowe in the work [14] cites many purposes of fluids in grinding:

- mechanical and chemo-physical lubrication;

- cooling the grinding wheel and the workpiece;

- flushing of the debris away from the contact area;

- warding abrasive dust and harmful vapours off; b)

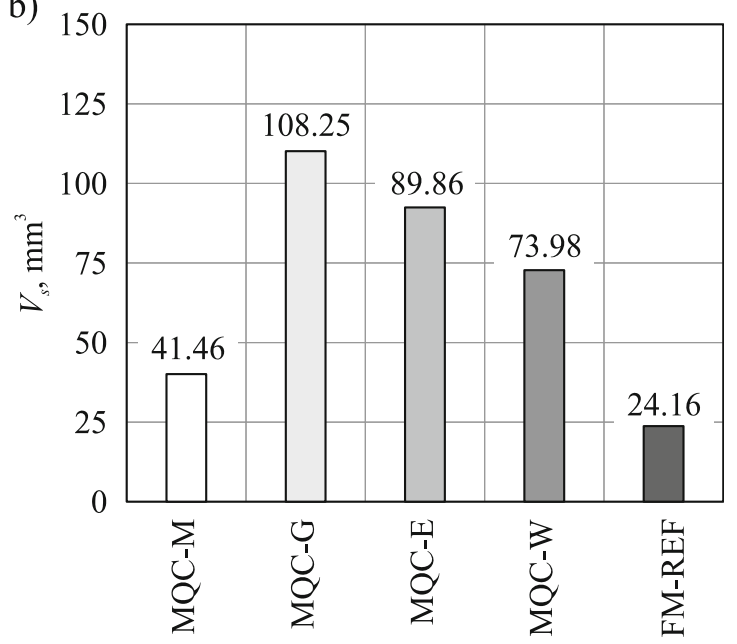

d)

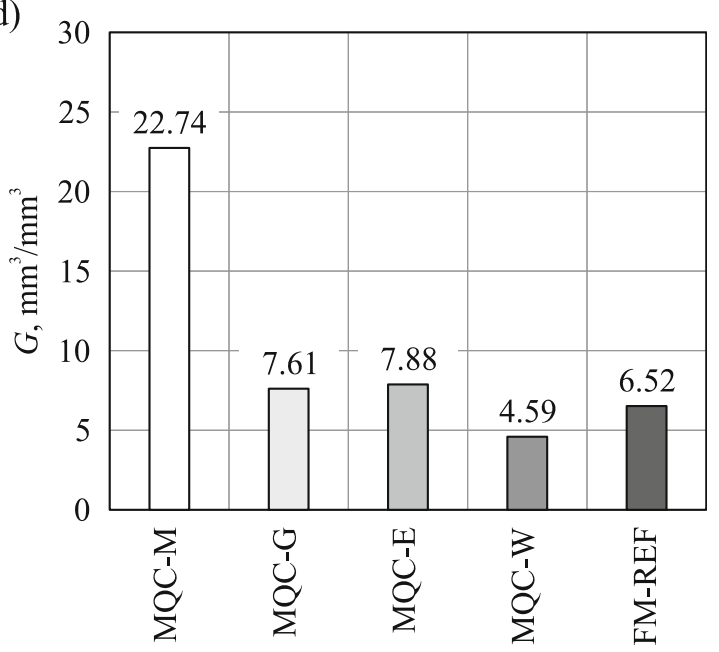

grinding power $\Delta P_{a v}$ b Volumetric grinding wheel wear $V_{s}$. $\mathbf{c}$ Material removal $V_{w}$ d Grinding ratio $G=V_{w} / V_{s}$

- corrosion protection.

However, the application of grinding fluids does not always lead to achieving the desired effects. Therefore, the methods and techniques of the delivery of the grinding fluids to the contact zone with the workpiece are highly significant. As a consequence, it is necessary to aim to the maximization of the grinding fluids which go directly to the grinding zone. The most common delivery method is conventional flood cooling, in which a large quantity of coolant is delivered continuously into the grinding zone at a low-pressure [16, 17].

Compared to internal cylindrical grinding, conventional flood cooling is inefficient. First of all, conventional flood cooling leads to non-uniform grinding fluid delivery. Secondly, the coolant's efficiency depends on axial table feed. Moreover, only a fraction of coolant hits the grinding zone directly. Therefore, more effective coolant delivery methods have been employed such as the use of a shoe or jet nozzle [18-20], atomizer and spray nozzle or minimum quantity 
a) WORKPIECE SURFACE AFTER THE INTERNAL CYLINDRICAL GRINDING PROCESS OF INCONEL ${ }^{\circledR}$ ALLOY 718 UNDER MQC-M CONDITIONS

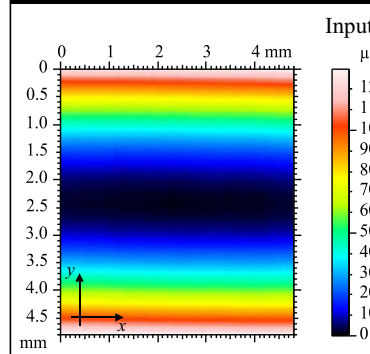

AMPLITUDE PARAMETERS $S a=0.210 \mu \mathrm{m}, S p=1.96 \mu \mathrm{m}$ $S t=3.77 \mu \mathrm{m}, S v=1.82 \mu \mathrm{m}$, Ssk $=0.078, S k u=3.95$

FILTERING

Filter type: Gaussian I Cut-off: $0.25 \mathrm{~mm}$ I Surface size: $4.56 \times 4.55 \mathrm{~mm}(3786 \times 191$ points Filter size: $0.25 \times 0.25 \mathrm{~mm}(208 \times 11$ points $)$

MEASUREMENT CONDITION

Area of a single topography (axes x, y, z): $4.80 \times 4.80 \times 0.13 \mathrm{~mm}$ I The number of profile points (axis x): 3994 I Distance between profile points (axis x): $1.2 \mu \mathrm{m}$

The number of profiles (axis y): 201 | Distance between profile points (axis y): $24 \mu \mathrm{m}$ I Measuring time: $87 \mathrm{~min}$.

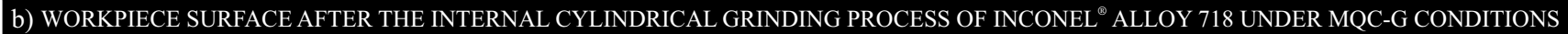

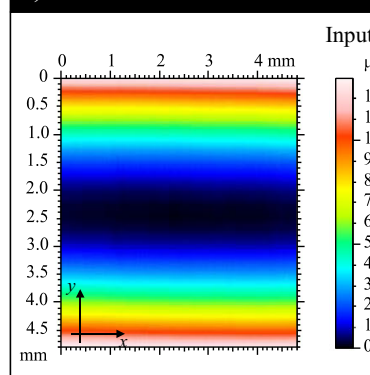

AMPLITUDE PARAMETERS $S a=0.236 \mu \mathrm{m}, S p=4.75 \mu \mathrm{m}$ $S t=6.42 \mu \mathrm{m}, S v=1.67 \mu \mathrm{m}$, $S s k=0.358, S k u=7.01$

FILTERING

Filter type: Gaussian I Cut-off: $0.25 \mathrm{~mm}$ I Surface size: $4.56 \times 4.55 \mathrm{~mm}(3786 \times 191$ points $)$ Filter size: $0.25 \times 0.25 \mathrm{~mm}(208 \times 11$ points $)$

MEASUREMENT CONDITION

Area of a single topography (axes x, y, z): $4.80 \times 4.80 \times 0.127 \mathrm{~mm}$ I The number of profile points (axis $\mathrm{x}$ ): 3786 I Distance between profile points (axis $\mathrm{x}$ ): $1.2 \mu \mathrm{m}$ The number of profiles (axis y): 191 | Distance between profile points (axis y): $24 \mu \mathrm{m}$ I Measuring time: $87 \mathrm{~min}$.

Fig. 4 Collection of selected results obtained for the GWAS $1-35 \times 10 \times$ 10-9A5X60L10VE01PI-50 after the internal cylindrical grinding process of Inconel ${ }^{\mathbb{B}}$ alloy 718 by a Hommel-Tester T-8000 stylus profilometer, produced by Hommelwerke GbmH, in the form of 2D surface maps (in

lubrication methods [21-23]. Despite the use of the above methods, the problem is still current and requires further intensive research [24]. Albeit possible, using the abovepresented methods during internal cylindrical grinding is problematic because of the grinding wheel's small dimensions and limited workspace. This is also possible by using the internal delivery grinding fluids system $[25,26]$. This system enables the coolant to go directly through the arbor and the intergranular free spaces into the grinding zone [23].

For several years, many studies covering the problems related with GFs have been published, showing that the usage of conventional flood coolants have become more problematic by virtue of economy, environmental pollution, and the health of employees [21, 22]. The usage of the fluids (including maintenance and waste disposal contributes) accounts for 7 indexed colors) with extracted a single profile, 3D surface topographies and calculated values of selected 3D parameters for a MQC-M and $\mathbf{b}$ MQC-G

$17 \%$ of the total manufacturing cost [27]. Therefore, a significant problem in the grinding process is the exploration of new, more environmentally friendly, energy saving and costeffective cooling alternatives which increase efficiency and result in creating the best surface finish.

The first alternative is using solid lubricants by the process of impregnation. These substances are nontoxic and easy to apply and, most of all, they substantially reduce machining costs [27-29]. The impregnation of a grinding wheel depends on its porosity. Open-grain wheels allow the impregnation of a whole abrasive tool, while close-grain wheels in turn allow impregnation only of the active surface. These actions may be taken by producers and also by the users themselves. They may adjust impregnate compositions to the technological needs of the tools [27, 29-32]. 
GWAS AFTER THE INTERNAL CYLINDRICAL GRINDING OF INCONEL ${ }^{\circledR}$ ALLOY 718 | MQC-M

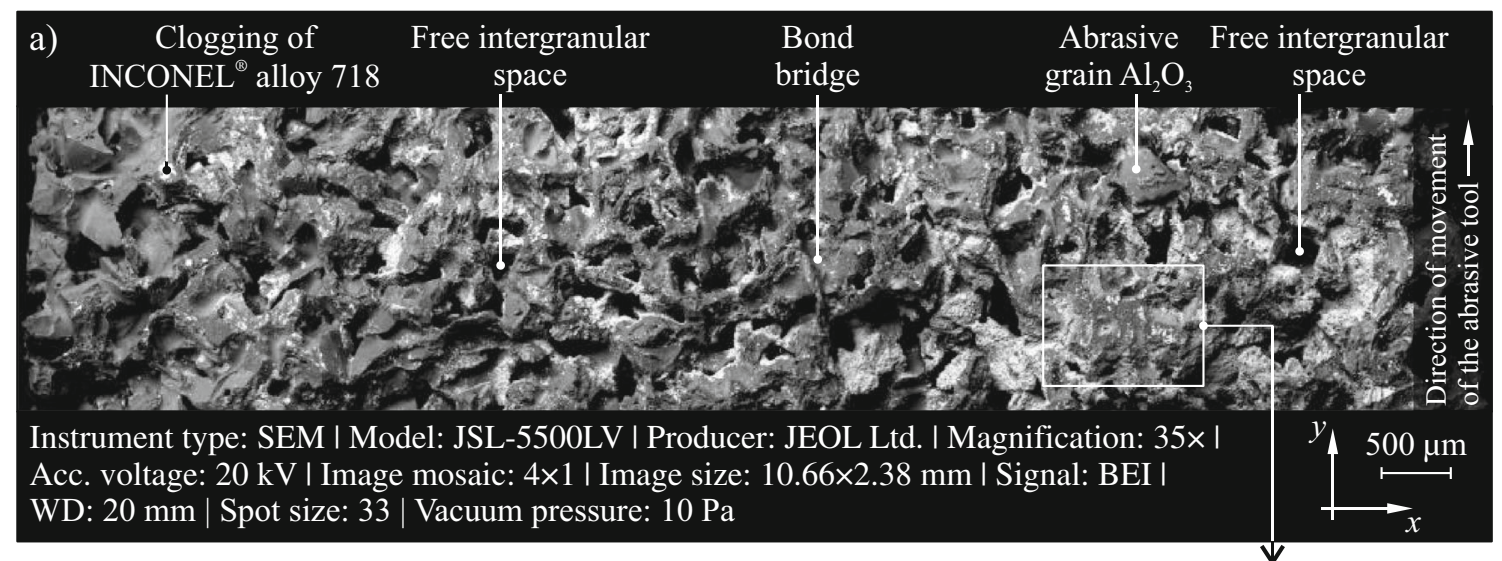

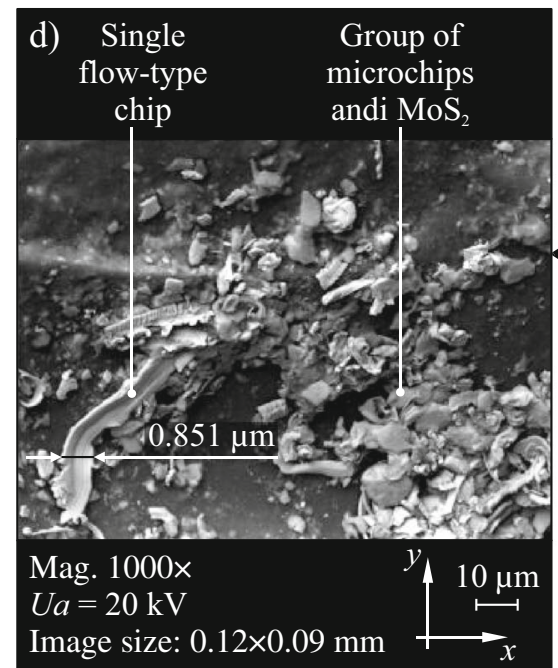

Fig. 5 Collection of selected results obtained for the GWAS after the internal cylindrical grinding process of Inconel ${ }^{\circledR}$ alloy 718 under MQC$\mathrm{M}$ conditions by the JSL-5500LV SEM produced by JEOL Ltd. a A vast panorama of the GWAS (mag. $\times 35$, size $10.66 \times 2.38 \mathrm{~mm}$ ). b SEM

Graphite, molybdenum disulfide, silicones, sulphur, waxes, resins etc. may be used as solid lubricants $[28,33]$.

A second alternative is minimum quantity lubrication (MQL), where the air and grinding fluid are mixed in a specially designed nozzle and accurately directed into the grinding zone [21-23, 34]. Comparing to the conventional flood cooling, the flow rate of the GF is about three or four orders of magnitude lower and amounts to $50-500 \mathrm{ml} / \mathrm{h}$. There are many known publications concerning MQL methods in grinding. However, the described techniques are ineffective in internal cylindrical grinding because of the limited space around the grinding wheel. The aim to solve this problem led the authors here to work out an innovative MQL method of delivering grinding fluid into the grinding zone in internal cylindrical grinding. The authors of the work [26] showed that usage of the method they proposed is able to achieve better results, comparing to the traditional MQL method, in the nickel alloy internal cylindrical grinding process.
If it is necessary to ensure adequate cooling, waterbased oil emulsions are used as coolant instead of oil in the MQL method. They are used when cooling cannot be carried out by oil. For this method Weinert et al. in the work [35] use the term Minimum Quantity Cooling (MQC). Although the lubricating properties of emulsions are significantly worse than those of oil, they are more advantageous than when water and air are used as coolant. Coolant expenditure in MQC processes is usually between 10 and $50 \mathrm{ml} / \mathrm{h}$ [35]. Priarone et al. [36] in the conducted tests of the cooling efficiency of the machining zone during the turning process of difficult-to-cut steels applied the MQC method with a coolant flow rate from 6.5 to $115 \mathrm{ml} / \mathrm{h}$. Studies have shown that cooling the machining zone with MQC using emulsions increases tool life with respect to the use of water spray as a coolant. In addition, it has been shown that increasing the aerosol flow rate further reduces tool wear [35]. As, so far, the MQC 
GWAS AFTER THE INTERNAL CYLINDRICAL GRINDING OF INCONEL ${ }^{\oplus}$ ALLOY 718 | MQC-G

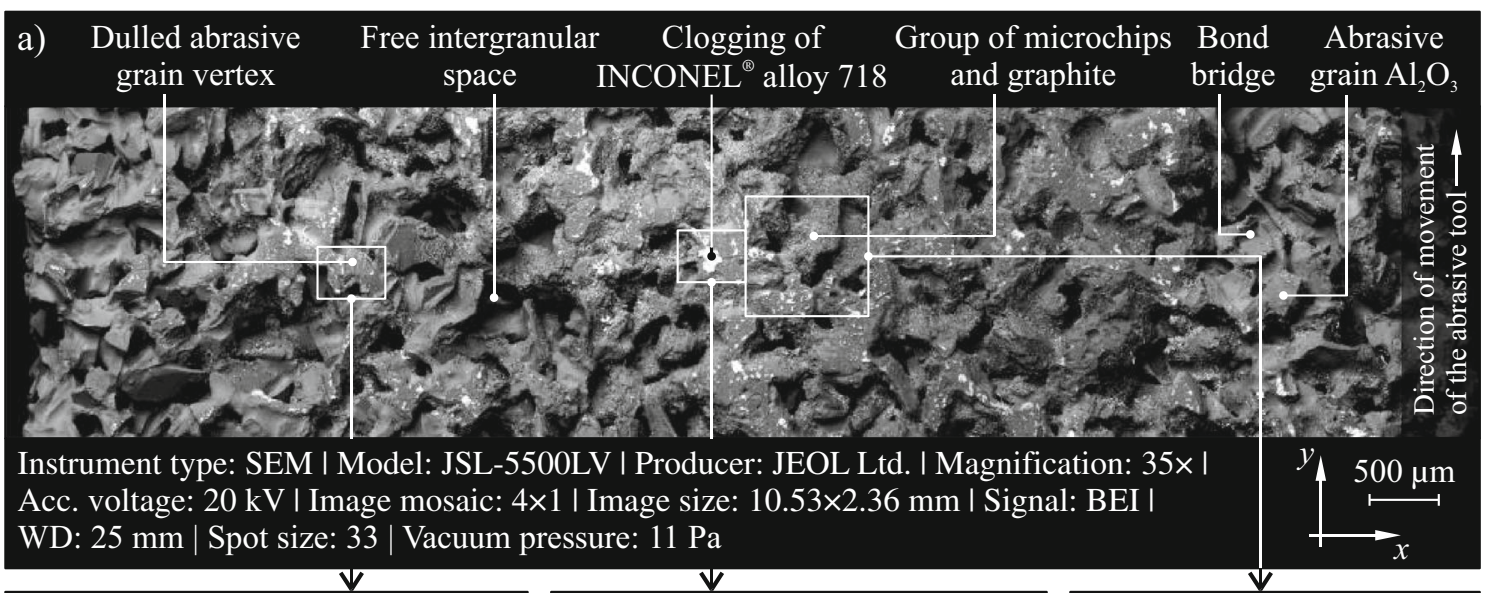

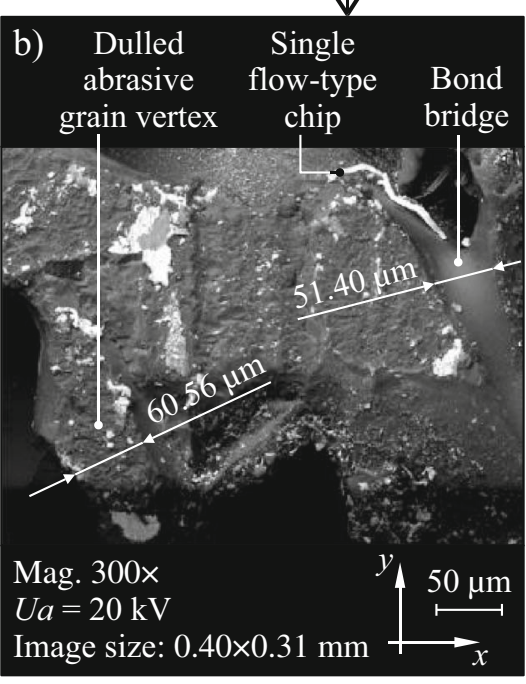

Fig. 6 Collection of selected results obtained for the GWAS after the internal cylindrical grinding process of Inconel ${ }^{\mathbb{R}}$ alloy 718 under MQC$\mathrm{G}$ conditions by the JSL-5500LV SEM produced by JEOL Ltd. a A vast panorama of the GWAS (mag. $\times 35$, size $10.53 \times 2.36 \mathrm{~mm}$ ). b SEM
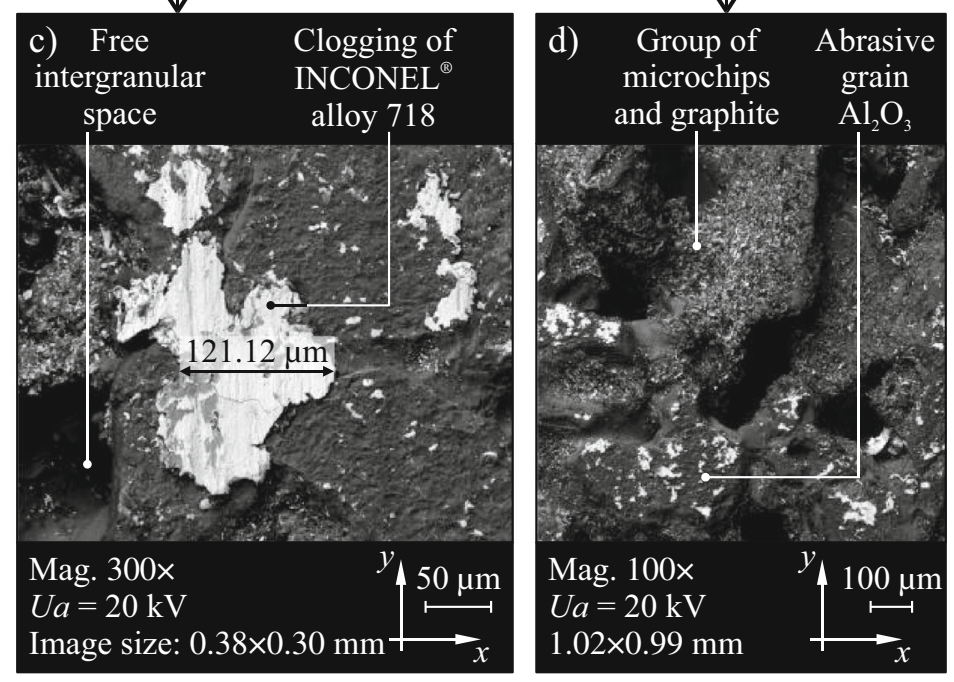

micrograph extracted from $($ a) $($ mag. $\times 300$, size $0.40 \times 0.31 \mathrm{~mm})$. c SEM micrograph extracted from (a) (mag. $\times 300$, size $0.38 \times 0.30 \mathrm{~mm}$ ). d SEM micrograph extracted from (a) (mag. $\times 100$, size $1.02 \times 0.99 \mathrm{~mm})$

method has not been widely used in industry, the elementary phenomena accompanying it are not yet as wellknown as in other methods of minimizing coolant expenditure.

The third alternative is the addition of nanoparticles to conventional lubricants. A research group from Qingdao Technological University has published several papers about new kind of Inconel ${ }^{\circledR}$ alloy 718 hybrid machining in recent years [37-40]. The researchers described a new MQL method in which where a new kind of GF was used-a nanofluid-and which was delivered to the grinding zone by MQL nozzle. As a nanofluid, an oil suspension of nanopowders were used. Wang et al. [37] carried out a comparative analysis of six nanofluids, namely $\mathrm{MoS}_{2}, \mathrm{SiO}_{2}$, diamond, carbon nanotubes, $\mathrm{Al}_{2} \mathrm{O}_{3}$ and $\mathrm{ZrO}_{2}$ (with a concentration of $6 \mathrm{wt} . \%$ in pure palm oil) on an efficiency of the Inconel ${ }^{\circledR}$ alloy 718 MQL plane grinding process. The quantity of nanofluid was $50 \mathrm{ml} / \mathrm{h}$. They referred their method to traditional MQL grinding with the same coolant quantity and flood cooling method with $60 \mathrm{l} / \mathrm{h}$ of coolant quantity also. As a result of the analysis, flood cooling was the least effective in any consideration. Compared to flood cooling, better surface roughness was obtained with the use the pure palm oil as a GF during MQL grinding. The presence of nanopowders in the grinding fluid as nanofluids significantly affected at the efficiency of the grinding process compared to results produced by traditional MQL grinding. Their research confirmed that the addition of nanopowders to GF may significantly influence the lubricative properties of a GF which can lead directly to a reduction of specific sliding grinding forces $F$, the coefficient of sliding friction $\mu$, and specific sliding grinding energy $e$. The addition of nanopowders to the grinding fluid may contribute to 
GWAS AFTER THE INTERNAL CYLINDRICAL GRINDING OF INCONEL ${ }^{\circledR}$ ALLOY 718 | MQC-E
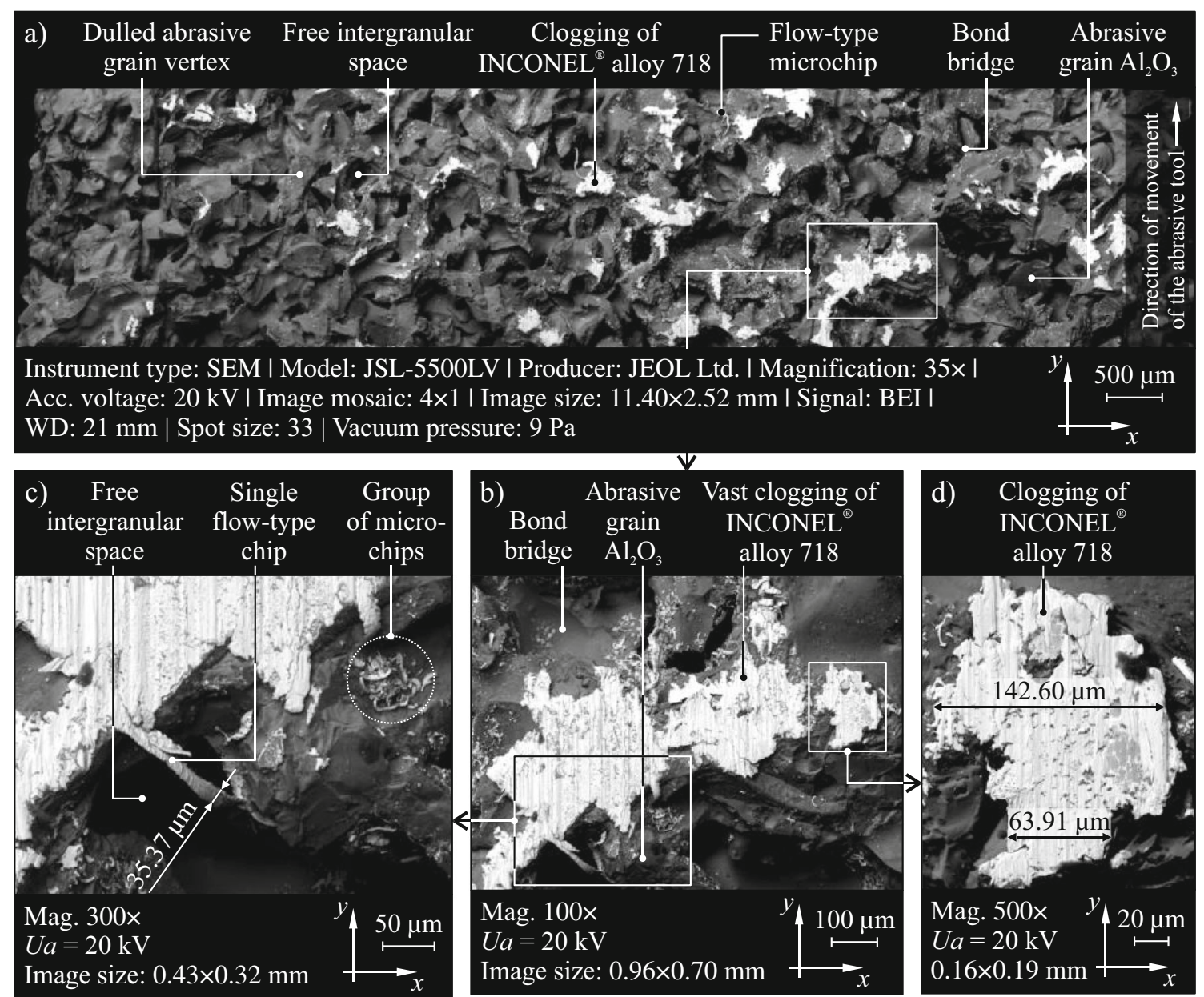

Fig. 7 Collection of selected results obtained for the GWAS after the internal cylindrical grinding process of Inconel ${ }^{\mathbb{R}}$ alloy 718 under MQCE conditions by the JSL-5500LV SEM produced by JEOL Ltd. a A vast panorama of the GWAS (mag. $\times 35$, size $11.40 \times 2.52 \mathrm{~mm}$ ). b SEM

a decrease of grinding wheel wear (an improvement in G-ratio values was apparent with the addition of nanoparticles to the base fluids) or the remediation of workpiece surface roughness also. The authors listed six nanopowders according to their increasing potential for use as abrasive nanofluids: $\mathrm{ZrO}_{2}<$ carbon nanotubes $<$ diamond $<\mathrm{MoS}_{2}<$ $\mathrm{SiO}_{2}<\mathrm{Al}_{2} \mathrm{O}_{3}$.

Sinha et al. in the work [41] presented a more environmentally friendly way of employing nanopowders in nanofluid usage in the small quantity lubrication (SQL) method. In their experiment, distilled water with the addition of detergent and silver and zinc oxide nanopowders as substances which reduce the adhesion of workpiece chips to the grinding wheel active surface (GWAS) were used as a GF. The experimental results of plane grinding of Inconel ${ }^{\circledR}$ alloy 718 using nanofluids were compared with the outcomes of grinding experiments under dry, wet and SQL with soluble oil. An energy-dispersive X-ray spectroscopy (EDS) analysis of the micrograph extracted from (a) (mag. $\times 100$, size $0.96 \times 0.70 \mathrm{~mm})$. c SEM micrograph extracted from (b) (mag. $\times 300$, size $0.36 \times 0.32 \mathrm{~mm}$ ). d SEM micrograph extracted from $(\mathbf{b})(\mathrm{mag} . \times 500$, size $0.16 \times 0.19 \mathrm{~mm})$

grinding wheels' active surface after grinding were confirmed the pertinence of the hypothesis that was originally conceived by the authors. From their study, it can be concluded that application of nanofluids resulted in a minimization of grinding forces, the coefficient of friction, and an improvement in ground surface integrity. Zinc oxide as a nanofluid showed better grinding responses mainly because of improved lubrication behaviour. This is primarily due to a better wettability that has induced a stable lubricious film on the contacting surfaces even at a higher temperature. During dry grinding, micro cracks on ground surface are observed. This also results in oxidation of the workpiece surface and renewed deposition of cut-off material at its surface also. Using silver or zinc oxide water dispersion practically causes complete elimination of these adverse phenomena. The findings of this work could be regarded as a first step towards the green and sustainable grinding of high strength superalloys. 
GWAS AFTER THE INTERNAL CYLINDRICAL GRINDING OF INCONEL ${ }^{\circledR}$ ALLOY 718 | MQC-W

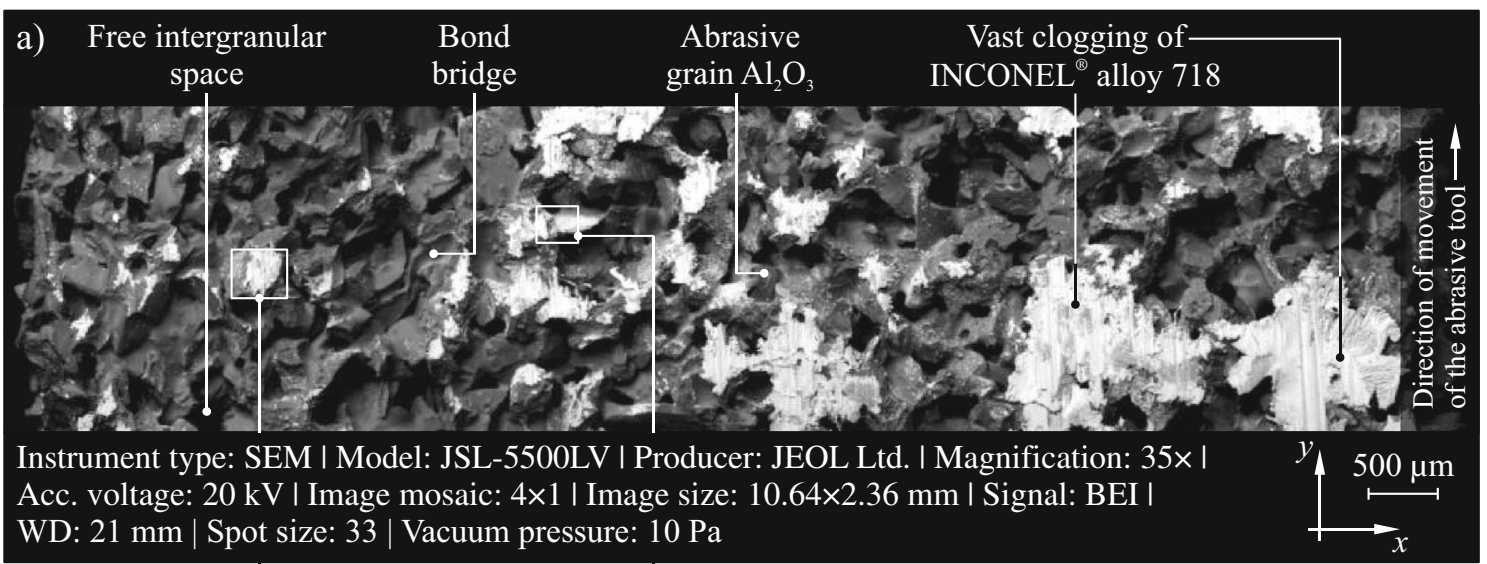

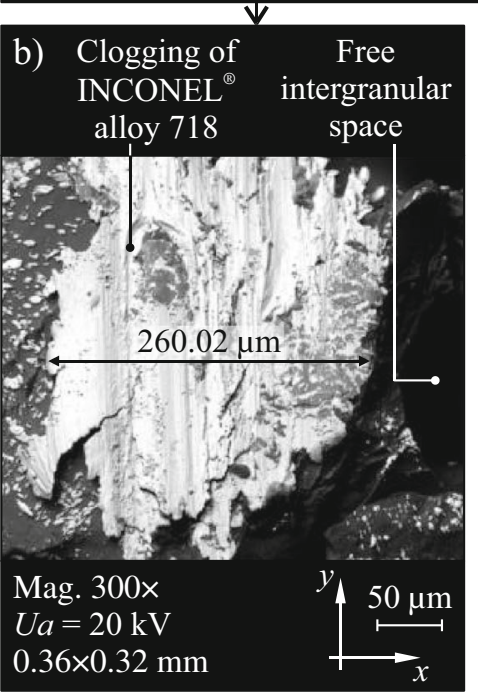

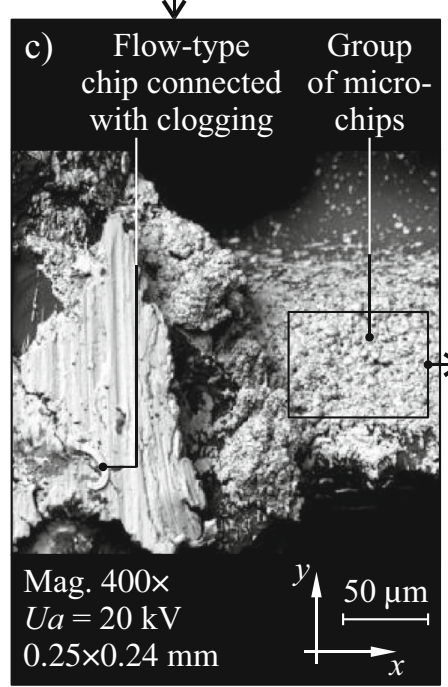

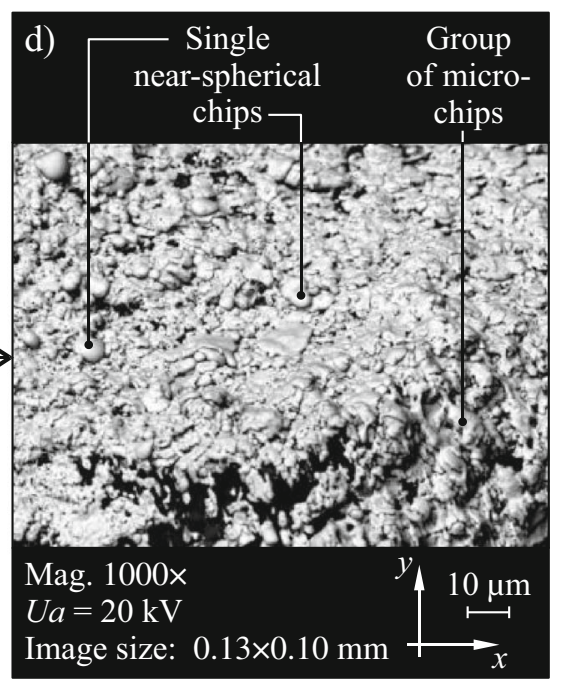

Fig. 8 Collection of selected results obtained for the GWAS after the internal cylindrical grinding process of Inconel ${ }^{\mathbb{R}}$ alloy 718 under MQCW conditions by the JSL-5500LV SEM produced by JEOL Ltd.. a A vast panorama of the GWAS (mag. $\times 35$, size $10.64 \times 2.36 \mathrm{~mm}$ ). b SEM

\section{Methodology of experimental studies}

\subsection{Main goal}

The main goal of these experimental studies was determining the influence of the supply of a GF doped with powdered graphite and $\mathrm{MoS}_{2}$ into the machining zone with the MQC method (via a nozzle that creates a water spray) on the course and results of the reciprocating internal cylindrical grinding of rings made from Inconel ${ }^{\circledR}$ alloy 718 . The innovation of the described research is based on the fact that for the first time, minimum quantity cooling with molybdenum disulfide and graphite-based microfluids has been adapted to the specific requirements of the internal cylindrical grinding process. In the following sections, the details related with conditions in which the experimental studies were carried out, as well as results of the experiments along with their analyses, were given. micrograph extracted from (a) (mag. $\times 300$, size $0.36 \times 0.32 \mathrm{~mm})$. c SEM micrograph extracted from (a) (mag. $\times 400$, size $0.25 \times 0.24 \mathrm{~mm}$ ). d SEM micrograph extracted from $($ c) $($ mag. $\times 1000$, size $0.13 \times$ $0.10 \mathrm{~mm}$ )

\subsection{Characteristics of the method of cooling the grinding zone with a minimum flow rate (MQC) with fluids doped with powdered lubricating and antiadhesive substances}

In view of the above, experimental studies were carried out whose aim was to determine the efficiency of such a method of delivering powdered lubricating and anti adhesive substances in the conditions of the internal cylindrical grinding process. The experimental setup was constructed on the basis of an RUP-28P grinding machine and equipped with a minimal atomizer ZMINMS, (Fig. 1), through which compressed air delivered three types of GF into the grinding zone, with a minimum flow rate of $Q_{G F}=1080 \mathrm{ml} / \mathrm{h}$. As a result, the grinding fluids were water aerosols created by the spraying nozzle powered with air at a pressure of $0.8 \mathrm{MPa}$, which delivered the following into the grinding zone: 
GWAS AFTER THE INTERNAL CYLINDRICAL GRINDING OF INCONEL $^{\circledR}$ ALLOY 718 | FM-REF

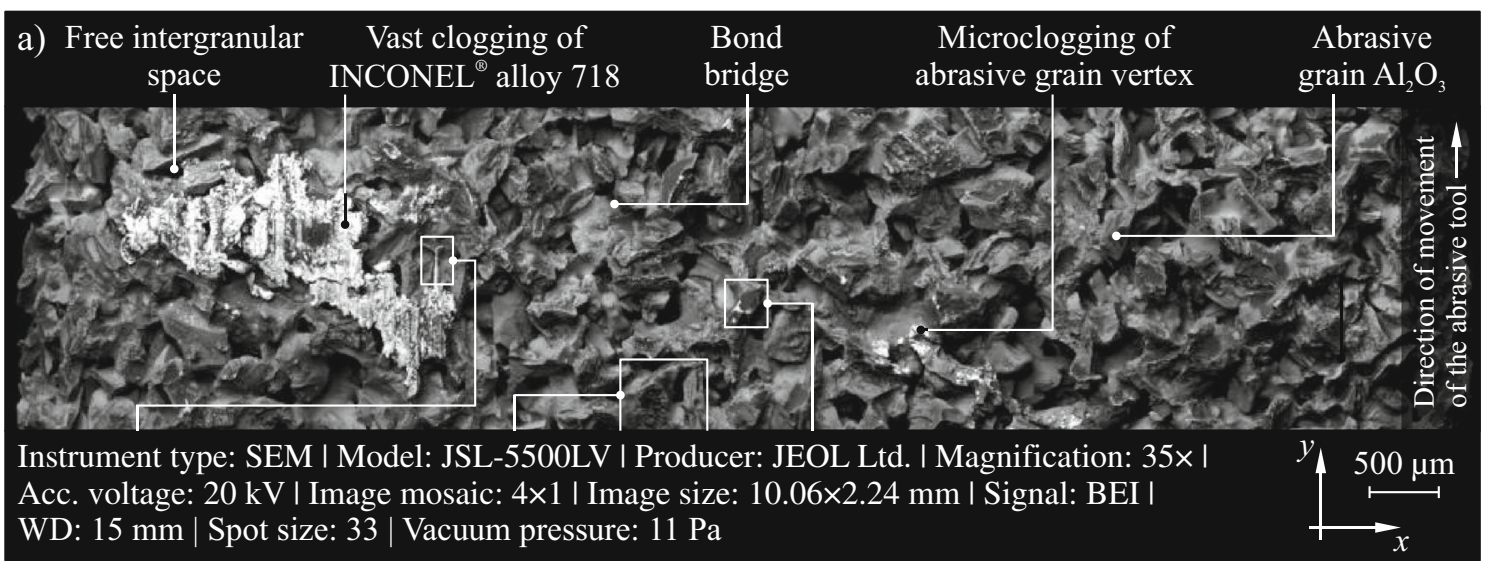

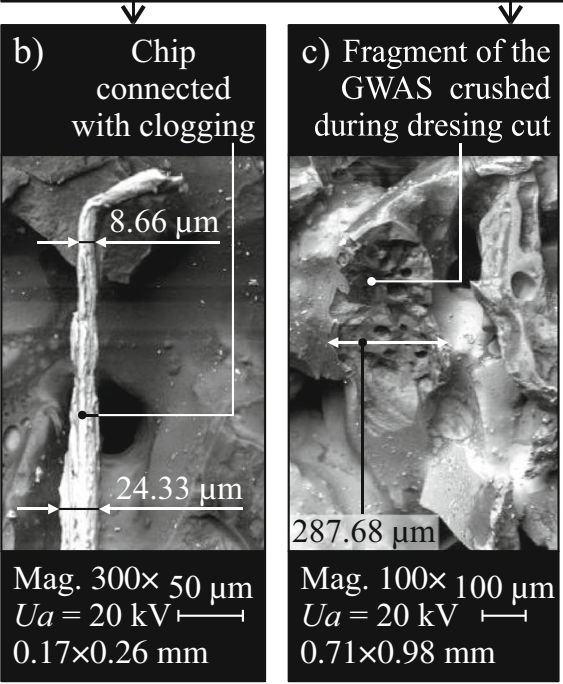

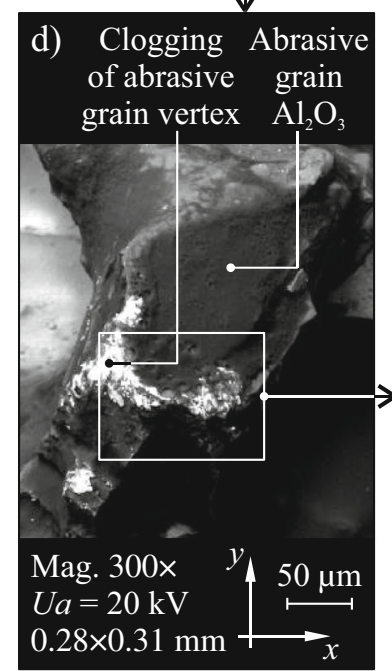

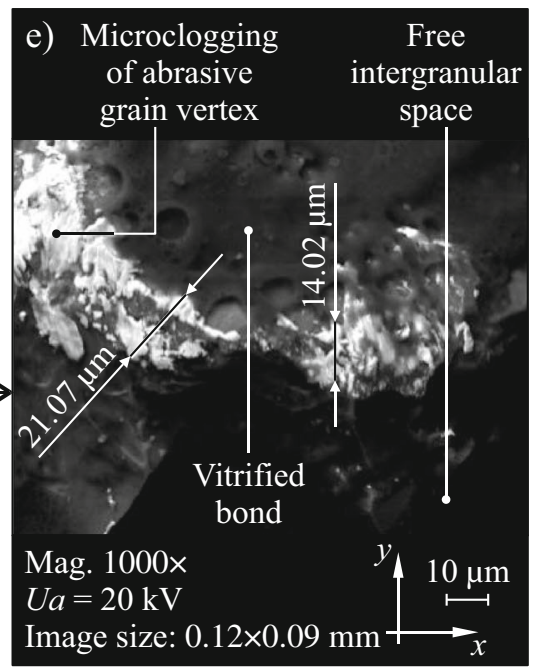

Fig. 9 Collection of selected results obtained for the GWAS after the internal cylindrical grinding process of Inconel ${ }^{\mathbb{R}}$ alloy 718 under FMREF conditions by the JSL-5500LV SEM produced by JEOL Ltd. a A vast panorama of the GWAS (mag. $\times 35$, size $10.06 \times 2.24 \mathrm{~mm}$ ). b SEM

- water slurry (demineralized water) $\mathrm{MoS}_{2}$ with a concentration of $30 \mathrm{~g} / \mathrm{dm}^{3}$,

- water slurry (demineralized water) of graphite with a concentration of $30 \mathrm{~g} / \mathrm{dm}^{3}$,

- $5 \%$ water solution of Syntilo RHS oil (Castrol Ltd., Liverpool, UK) (reference GF-standard emulsion delivered with a minimum flow rate),

pure demineralized water (reference GF-non-doped with powdered graphite or $\mathrm{MoS}_{2}$ ).

The GF was prepared by doping powdered graphite and $\mathrm{MoS}_{2}$ in to the spraying phase which, in this case, was demineralized water. In the applied graphite powder, over $70 \%$ of grains were characterized by a diameter in a range $0-30 \mu \mathrm{m}$. In the case of $\mathrm{MoS}_{2}$ Molykote $^{\circledR}$ (Dow Corning Corp., Auburn, AL, USA), microsize powder was used. micrograph extracted from (a) (mag. $\times 300$, size $0.17 \times 0.26 \mathrm{~mm})$. c SEM micrograph extracted from (a) (mag. $\times 100$, size $0.71 \times 0.98 \mathrm{~mm}$ ). d SEM micrograph extracted from (a) (mag. $\times 300$, size $0.28 \times 0.31 \mathrm{~mm})$. e SEM micrograph extracted from $(\mathbf{d})(\mathrm{mag} . \times 1000$, size $0.12 \times 0.09 \mathrm{~mm})$

\subsection{Grinding wheel and workpiece}

Studies were carried out on the process of internal cylindrical grinding with a grinding wheel's peripheral surface. What was determined in them were values of parameters that describe the condition of the machined surface and the GWAS with a technical marking of 1-35 × 10 × 10-9A5X60L10VE01PI-50 (Andre Abrasive Articles Sp. z o.o. Sp. k., Koło, Poland) during the machining of Inconel ${ }^{\circledR}$ alloy 718 .

\subsection{Conditions of the grinding process}

The grinding process was carried out in conditions of cooling and lubricating using the MQC method with a flow rate of $Q_{G F}=1080 \mathrm{ml} / \mathrm{h}$ (four GF types characterized in Section 2.2) and, as a reference, in the conditions of WET cooling with a flow rate of $Q_{G F}=2.7 \mathrm{l} / \mathrm{min}$. In each of the above-mentioned cases, 
Fig. 10 Collection of selected results obtained for the GWAS after the internal cylindrical grinding process of Inconel ${ }^{\mathbb{B}}$ alloy 718 during the image analysis carried out in ImagePro $^{\circledR}$ Plus 5.1 software for MQCM. a Input SEM micrograph of the GWAS. b Image after the binarization process. c Selected geometrical parameters of objects in the image after binarization (GWAS cloggings)
GWAS AFTER THE INTERNAL CYLINDRICAL GRINDING OF INCONEL ${ }^{\circledR}$ ALLOY 718 | MQC-M
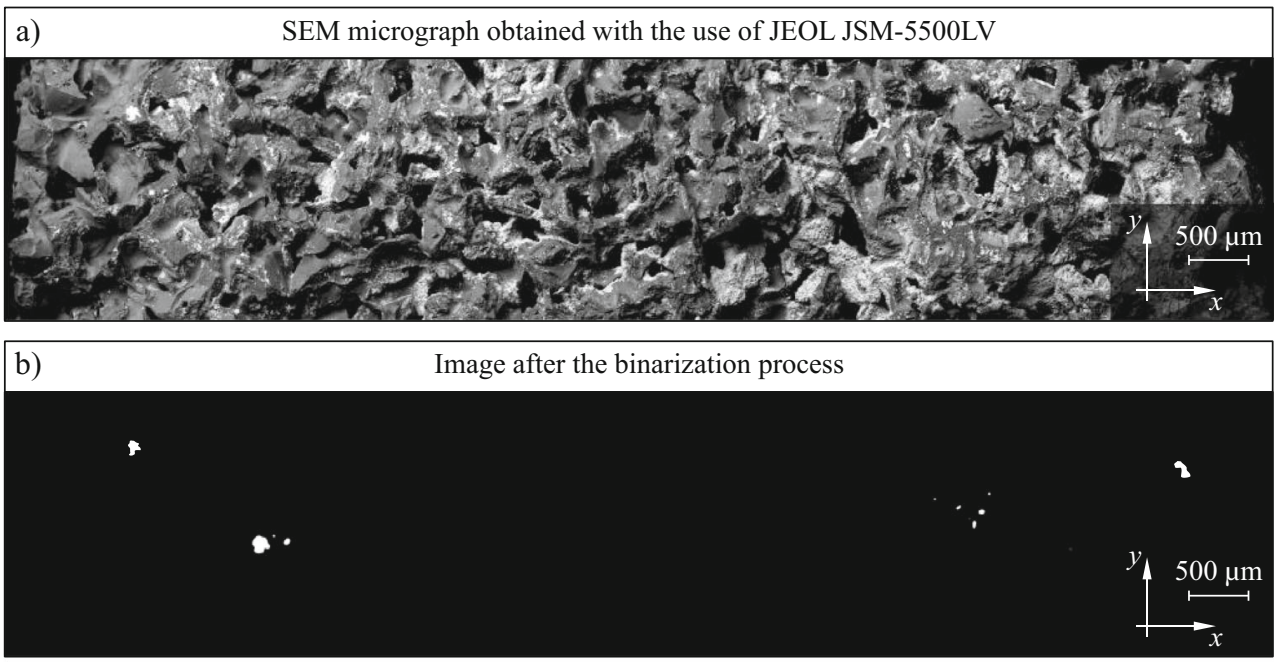

c) Selected geometrical parameters of objects in the image after binarization (GWAS cloggings)

\begin{tabular}{|cccccccc|}
\hline Parameter & Symbol & $\begin{array}{c}\text { Min. } \\
\text { value }\end{array}$ & $\begin{array}{c}\text { Max. } \\
\text { value }\end{array}$ & Mean & Std. Dev. & Sum & Unit \\
\hline $\begin{array}{c}\text { Number } \\
\text { of objects }\end{array}$ & $n$ & - & - & - & - & 10 & - \\
\hline Area & $A n$ & 11.42 & 4851.42 & 693.14 & 163.72 & 6931.42 & $\mu \mathrm{m}^{2}$ \\
\hline Perimeter & $P e$ & 5.71 & 461.08 & 110.42 & 126.91 & 1104.48 & $\mu \mathrm{m}$ \\
\hline Length & $l$ & 2.85 & 138.40 & 38.54 & 38.45 & 385.65 & $\mu \mathrm{m}$ \\
\hline Width & $w$ & 2.85 & 131.91 & 29.82 & 36.08 & 298.37 & $\mu \mathrm{m}$ \\
\hline Feret min. & $F_{\min }$ & 2.85 & 131.88 & 29.45 & 36.14 & 294.74 & $\mu \mathrm{m}$ \\
\hline Feret max. & $F_{\max }$ & 4.02 & 147.00 & 40.20 & 40.37 & 400.20 & $\mu \mathrm{m}$ \\
\hline
\end{tabular}

45] equipped with an SDD EDS OmegaMax ${ }^{\mathrm{TM}}$ detector by the same producer.

The experimental studies concerned internal cylindrical grinding in Inconel ${ }^{\circledR}$ alloy 718 , which is classified as a hardto-cut material, mainly due to the fact that it creates long ductile chips during machining. In reference to this, one of the most important criteria of assessing the state of grinding wheel wear is the area of cloggings analyzed on its active surface. This parameter was measured on the basis of SEM micrographs acquired with the electron microscope scanning technique and which were subjected to quantitative analysis using image and analysis techniques. Specialist software, namely Image-Pro ${ }^{\circledR}$ Plus 5.1 by Media Cybernetics, Inc. (Rockville, MD, USA) was used for this purpose.

\section{Results and discussion}

Analysis of the experimental studies' results was divided into four stages concerning: 
Fig. 11 Collection of selected results obtained for the GWAS after the internal cylindrical grinding process of Inconel ${ }^{\mathbb{B}}$ alloy 718 during the image analysis carried out in ImagePro ${ }^{\circledR}$ Plus 5.1 software for MQCG. a Input SEM micrograph of the GWAS. b Image after the binarization process. c Selected geometrical parameters of objects in the image after binarization (GWAS cloggings)

\section{GWAS AFTER THE INTERNAL CYLINDRICAL GRINDING OF INCONEL ${ }^{\oplus}$ ALLOY $718 \mid$ MQC-G}
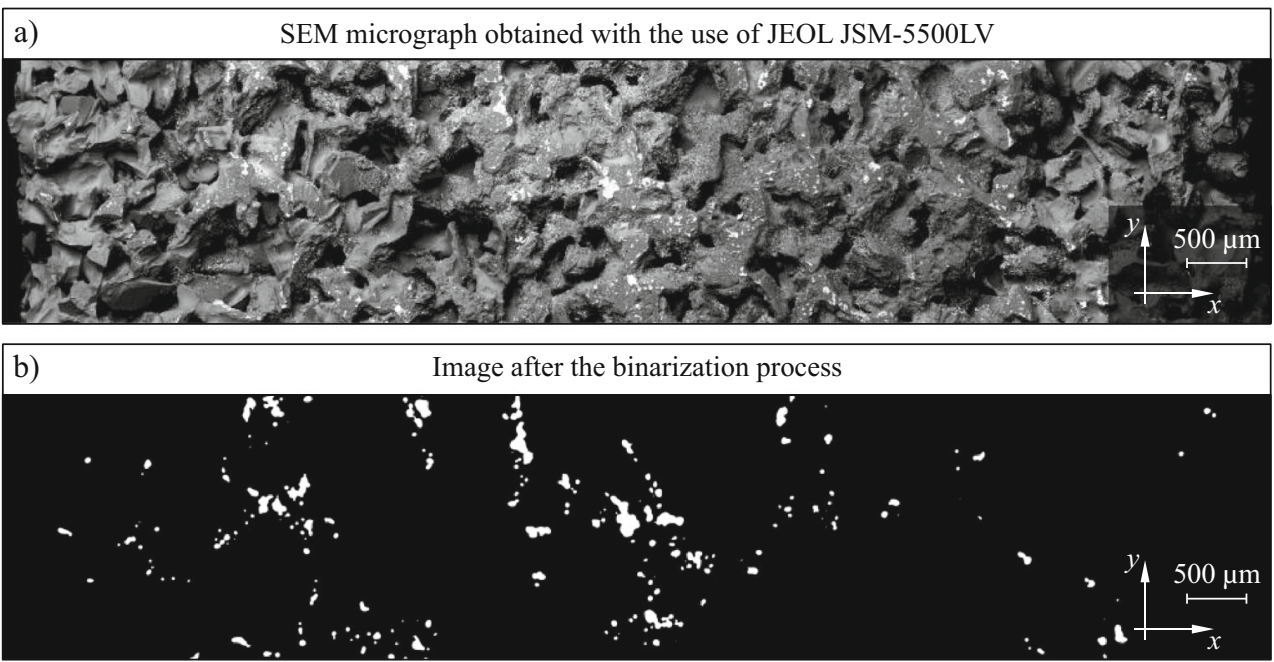

\begin{tabular}{|cccccccc|}
\hline c) & \multicolumn{6}{c}{ Selected geometrical parameters of objects in the image after binarization (GWAS cloggings) } \\
\hline Parameter & Symbol & $\begin{array}{c}\text { Min. } \\
\text { value }\end{array}$ & $\begin{array}{c}\text { Max. } \\
\text { value }\end{array}$ & Mean & Std. Dev. & Sum & Unit \\
\hline $\begin{array}{c}\text { Number } \\
\text { of objects }\end{array}$ & $n$ & - & - & - & - & 210 & - \\
\hline Area & $A n$ & 2.85 & 12165.00 & 783.62 & 1442.14 & 164562.00 & $\mu^{2}$ \\
\hline Perimeter & $P e$ & 2.85 & 1716.20 & 146.08 & 160.48 & 31280.28 & $\mu \mathrm{m}$ \\
\hline Length & $l$ & 0 & 623.65 & 54.14 & 56.60 & 11370.54 & $\mu \mathrm{m}$ \\
\hline Width & $w$ & 0 & 167.31 & 34.68 & 28.22 & 7285.91 & $\mu \mathrm{m}$ \\
\hline Feret min. & $F_{\min }$ & 0 & 167.22 & 33.80 & 27.94 & 7100.71 & $\mu \mathrm{m}$ \\
\hline Feret max. & $F_{\max }$ & 0 & 356.28 & 54.77 & 57.20 & 11502.28 & $\mu \mathrm{m}$ \\
\hline
\end{tabular}

\subsection{Evaluation of grinding process effectiveness}

basis of the average grinding power increase $\Delta P_{a v}$ grinding wheel volume wear $V_{s}$, material removal $V_{w}$ and $G$ grinding index (Section 3.1),

- machined surface roughness analysis on the basis of microtopographies measured with stylus profilometry (Section 3.2),

- assessment of the GWAS clogging of the workpiece material on the basis of qualitative and quantitative analysis of SEM micrographs acquired by a JSM-5500LV scanning electron microscope (Section 3.3),

- EDS microanalyses of elemental distribution and mapping their distribution on the GWAS, determined using an Explorer ${ }^{\mathrm{TM}}$ scanning electron microscope with an SDD EDS OmegaMax ${ }^{\mathrm{TM}}$ detector by the same producer (Section 3.4).

To order the markings used in analyses concerning the five considered options of cooling and lubricating the grinding zone, their abbreviations were introduced as explained in Table 2.
Analysis of the obtained experimental studies results showed that in the majority of cases it was possible to execute the machining until the complete removal of the total machining allowance, which was $a_{e}$ tot $=0.75 \mathrm{~mm}$. Only in grinding in the conditions of the MQC method and a GF in the form of demineralized water aerosol (MQC-W) did the limiting value of grinding power increase $\Delta P_{l}=510 \mathrm{~W}$ occur first, which caused termination of the machining process after $t_{g}$ tot $=439 \mathrm{~s}$. The results of the machining power increase measurements $\Delta P$ during internal cylindrical grinding in five different options of machining zone cooling and lubricating conditions are presented in Fig. 2.

In addition, Fig. 3 presents values of selected parameters describing the effectiveness of the examined grinding process for the five above-mentioned cooling and lubricating conditions options, determined on the basis of data from the whole grinding wheel life period:

- average grinding power increase $\Delta P_{a v}-$ Fig. 3a, 
Fig. 12 Collection of selected results obtained for the GWAS after the internal cylindrical grinding process of Inconel ${ }^{\mathbb{B}}$ alloy 718 during the image analysis carried out in ImagePro $^{\circledR}$ Plus 5.1 software for MQCE. a Input SEM micrograph of the GWAS. b Image after the binarization process. c Selected geometrical parameters of objects in the image after binarization (GWAS cloggings)

\section{GWAS AFTER THE INTERNAL CYLINDRICAL GRINDING OF INCONEL ${ }^{\oplus}$ ALLOY 718 | MQC-E}
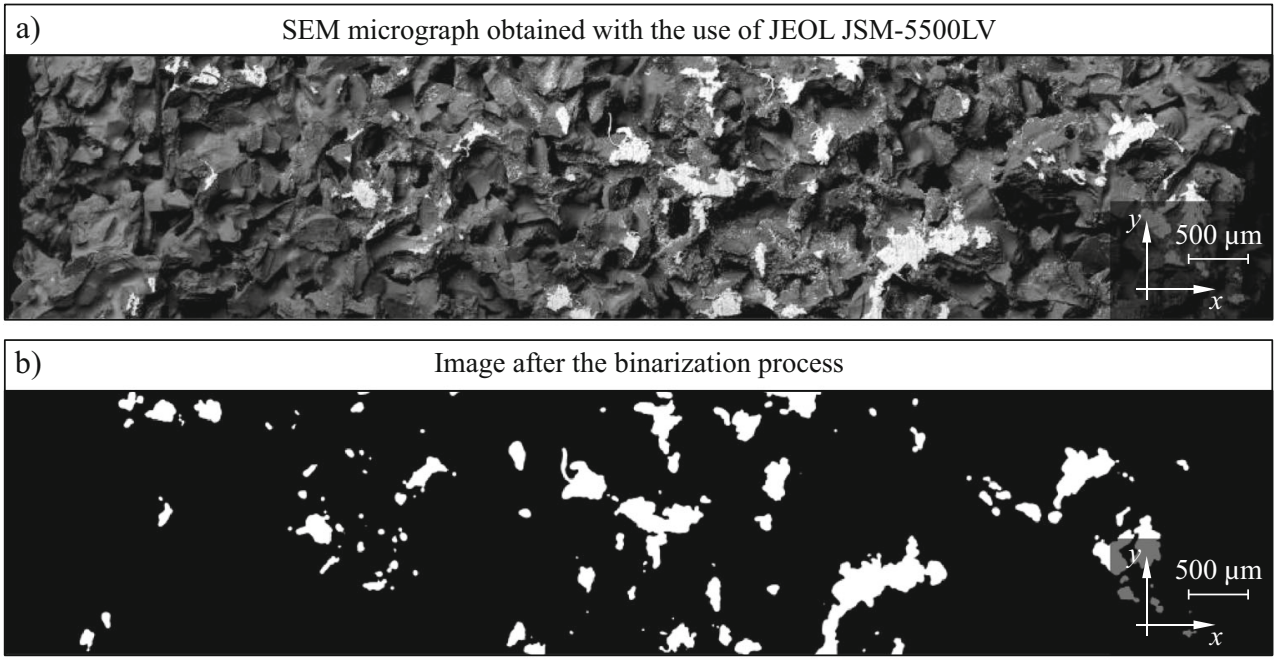

\begin{tabular}{|cccccccc|}
\hline c) & \multicolumn{6}{c|}{ Selected geometrical parameters of objects in the image after binarization (GWAS cloggings) } \\
\hline Parameter & Symbol & $\begin{array}{c}\text { Min. } \\
\text { value }\end{array}$ & $\begin{array}{c}\text { Max. } \\
\text { value }\end{array}$ & Mean & Std. Dev. & Sum & Unit \\
\hline $\begin{array}{c}\text { Number } \\
\text { of objects }\end{array}$ & $n$ & - & - & - & - & 122 & - \\
\hline Area & $A n$ & 3.12 & 104706.00 & 4900.18 & 12154.18 & 597825.00 & $\mu \mathrm{m}^{2}$ \\
\hline Perimeter & $P e$ & 3.12 & 4416.68 & 407.43 & 583.71 & 49710.15 & $\mu \mathrm{m}$ \\
\hline Length & $l$ & 0 & 1370.43 & 140.09 & 178.84 & 17092.87 & $\mu \mathrm{m}$ \\
\hline Width & $w$ & 0 & 606.37 & 86.43 & 104.75 & 10549.15 & $\mu \mathrm{m}$ \\
\hline Feret min. & $F_{\min }$ & 0 & 609.50 & 134.65 & 102.43 & 10268.81 & $\mu \mathrm{m}$ \\
\hline Feret max. & $F_{\max }$ & 0 & 1371.15 & 141.46 & 180.09 & 17262.21 & $\mu \mathrm{m}$ \\
\hline
\end{tabular}

\begin{abstract}
- grinding wheel volume wear $V_{s}$-Fig. 3b,
- material removal $V_{w}-$ Fig. 3c,

- grinding index $G=V_{w} / V_{s}$-Fig. 3d.
\end{abstract}

Analysis of the experimental studies' results makes it possible to conclude that the most advantageous conditions of executing cylindrical grinding in Inconel $^{\circledR}$ alloy 718 were obtained in the case of using the system of a minimum GF flow rate with the MQC method (Figs. 2 and 3). The application of cooling and lubricating with the WET method caused the exceeding of the grinding power increase threshold value after the shortest grinding wheel operation time (189 sFig. 2e) and it was during its course that the highest mean value of these parameters was measured $\left(\Delta P_{a v}=344 \mathrm{~W}-\right.$ Fig. 3a). During grinding in conditions of delivering the GF with the MQC method, the mean grinding power increase had slightly lower values in a range from 220 to $311 \mathrm{~W}$ (Fig. 3a).

Analyzing the differences in research results obtained for specific GF types delivered with the MQC method, it may be concluded that the application of GFs doped with $\mathrm{MoS}_{2}$ and graphite, as well as emulsions, allows for stable execution of the grinding process in a relatively long period of time (in the above-described studies $t_{g}=900 \mathrm{~s}-$ Fig. 2a-c). The delivery of pure demineralized water aerosol into the grinding zone caused the exceeding of the threshold value $\Delta P_{l}$ after $t_{g}=439 \mathrm{~s}$ (Fig. $2 \mathrm{~d}$ ). This means that a lack of doping with powdered lubricating and antiadhesive substances in a solid state, or a lack of the addition of oil (in the case of emulsion), contributes considerably to limiting the GF lubricating properties and leads to substantial shortening of the grinding wheel life (Fig. 2).

Comparing the measured values of grinding wheel volume wear $V_{s}$ (Fig. 3b) and material removal $V_{w}$ (Fig. 3c), on which the grinding index $G$ value is directly dependent (Fig. 3d), it may be concluded that by far the most advantageous indexes were obtained in the case of grinding conditions with the delivery of demineralized water doped with $\mathrm{MoS}_{2}$ particles with the MQC method. In this case, the lowest grinding wheel volume wear $\left(V_{s}=41.46 \mathrm{~mm}^{3}\right)$ and the highest actual machined material removal rate $\left(V_{w}=942.91 \mathrm{~mm}^{3}\right)$ were observed, due to which the following grinding index value was obtained: $G=22.74 \mathrm{~mm}^{3} / \mathrm{mm}^{3}$ (Fig. 3). This value is three- 
Fig. 13 Collection of selected results obtained for the GWAS after the internal cylindrical grinding process of Inconel ${ }^{\mathbb{B}}$ alloy 718 during the image analysis carried out in ImagePro $^{\circledR}$ Plus 5.1 software for MQCW. a Input SEM micrograph of the GWAS. b Image after the binarization process. c Selected geometrical parameters of objects in the image after binarization (GWAS cloggings)

\section{GWAS AFTER THE INTERNAL CYLINDRICAL GRINDING OF INCONEL ${ }^{\circ}$ ALLOY 718 | MQC-W}
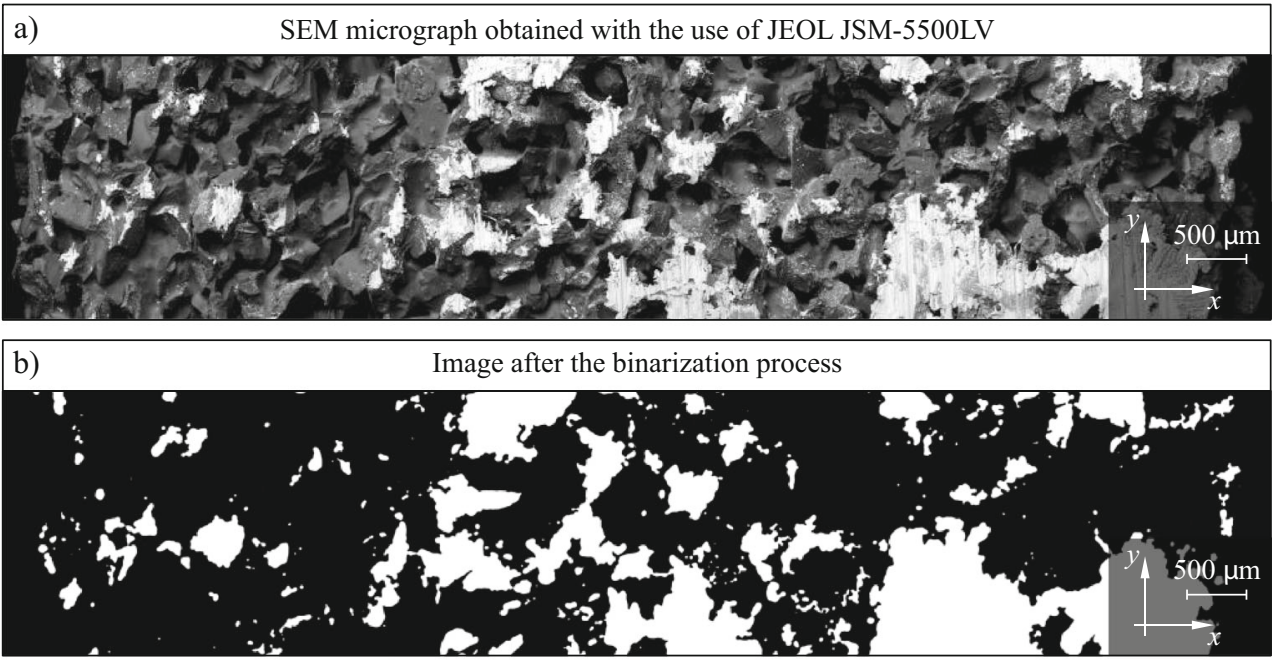

c) Selected geometrical parameters of objects in the image after binarization (GWAS cloggings)

\begin{tabular}{|cccccccc|}
\hline Parameter & Symbol & $\begin{array}{c}\text { Min. } \\
\text { value }\end{array}$ & $\begin{array}{c}\text { Max. } \\
\text { value }\end{array}$ & Mean & Std. Dev. & Sum & Unit \\
\hline $\begin{array}{c}\text { Number } \\
\text { of objects }\end{array}$ & $n$ & - & - & - & - & 300 & - \\
\hline Area & $A n$ & 5 & 1244175.00 & 11491.65 & 77189.15 & 3447495.00 & $\mu \mathrm{m}^{2}$ \\
\hline Perimeter & $P e$ & 5 & 17050.00 & 585.45 & 1530.85 & 17527.10 & $\mu \mathrm{m}$ \\
\hline Length & $l$ & 0 & 4896.75 & 185.40 & 411.45 & 55626.10 & $\mu \mathrm{m}$ \\
\hline Width & $w$ & 0 & 1864.65 & 112.15 & 222.85 & 33658.20 & $\mu \mathrm{m}$ \\
\hline Feret min. & $F_{\min }$ & 0 & 1910.00 & 107.65 & 215.40 & 32304.55 & $\mu \mathrm{m}$ \\
\hline Feret max. & $F_{\max }$ & 0 & 4912.70 & 188.10 & 415.35 & 56433.25 & $\mu \mathrm{m}$ \\
\hline
\end{tabular}

times higher than in the case of values obtained in the remaining four cases where $G=4.59-7.88 \mathrm{~mm}^{3} / \mathrm{mm}^{3}$. It may be therefore concluded that in the applied method of delivering the GF with a minimum flow rate in the form of aerosol (MQC method) through a single nozzle spraying towards the grinding zone (Fig. 1), doping demineralized water with $\mathrm{MoS}_{2}$ particles with a concentration of $30 \mathrm{~g} / \mathrm{dm}^{3}$ provides the most advantageous tribological conditions in the area of contact between the active abrasive grain apexes and the machined surface.

\subsection{Analysis of workpiece surface roughness}

Measurements of the workpieces' surface texture were carried out using a Hommel-Tester T8000 stylus profilometer. In all of the analyzed cases, they confirmed obtaining the desired values of parameters describing the machined surface roughness $(S a<0.63 \mu \mathrm{m})$. The most advantageous conditions were obtained in the case of delivering the GF doped with powdered $\mathrm{MoS}_{2}$ (MQC-M) and graphite (MQC-G) into the grinding zone using the MQC method.
Detailed surface texture analyses were thus conducted in reference to these two options. Figure 4a presents a comparison of the selected results of analyses of the workpiece surface roughness obtained with a Hommel-Tester T8000 stylus profilometer for the MQC-M option, while Fig. 4b presents an analogical comparison for the option abbreviated as MQC-G.

As the results obtained from analyzing the workpiece' surface texture indicate, in both of the analyzed options of grinding wheel cooling and lubrication conditions, insignificant surface roughness was obtained (Fig. 4). This is proved by values of selected roughness parameters which, for options MQC-M and MQC-G, are, respectively, as follows: the arithmetic mean deviation of the surface $S a=0.210 \mu \mathrm{m}$ and $0.236 \mu \mathrm{m}$; total height of the surface $S t=3.77 \mu \mathrm{m}$ and $6.42 \mu \mathrm{m}$; density of summits of the surface $S d s=950 \mathrm{pks} / \mathrm{mm}^{2}$ and $933 \mathrm{pks} / \mathrm{mm}^{2}$; and developed interfacial area ratio $S d r=0.297 \%$ and $0.341 \%$. Such values of surface texture parameters are indicative of the proper operation of the grinding wheel and favorable tribological conditions in the grinding zone in the analyzed options. 
Fig. 14 Collection of selected results obtained for the GWAS after the internal cylindrical grinding process of Inconel ${ }^{\mathbb{B}}$ alloy 718 during the image analysis carried out in ImagePro $^{\circledR}$ Plus 5.1 software for FMREF. a input SEM micrograph of the GWAS; b) image after the binarization process; c) selected geometrical parameters of objects in the image after binarization (GWAS cloggings)

GWAS AFTER THE INTERNAL CYLINDRICAL GRINDING OF INCONEL ${ }^{\circ}$ ALLOY 718 | FM-REF
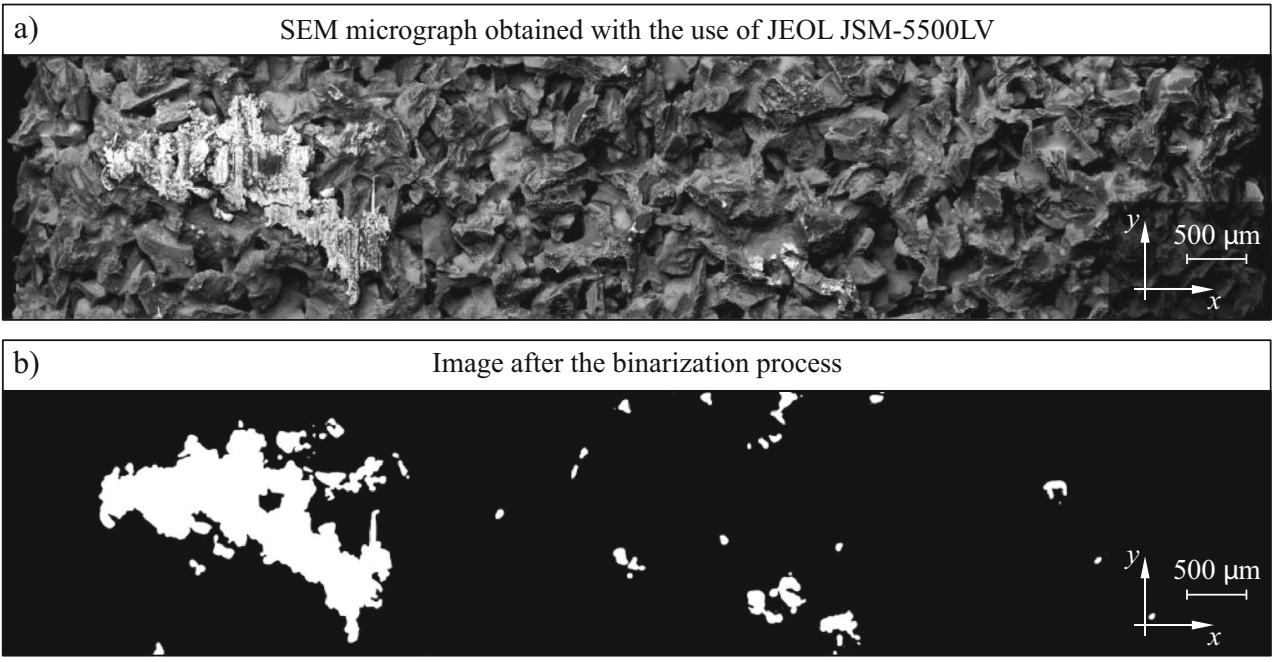

c) Selected geometrical parameters of objects in the image after binarization (GWAS cloggings)

\begin{tabular}{|cccccccc|}
\hline Parameter & Symbol & $\begin{array}{c}\text { Min. } \\
\text { value }\end{array}$ & $\begin{array}{c}\text { Max. } \\
\text { value }\end{array}$ & Mean & Std. Dev. & Sum & Unit \\
\hline $\begin{array}{c}\text { Number } \\
\text { of objects }\end{array}$ & $n$ & - & - & - & - & 52 & - \\
\hline Area & $A n$ & 2.77 & 479941.00 & 11765.61 & 65713.94 & 611633.00 & $\mu \mathrm{m}^{2}$ \\
\hline Perimeter & $P e$ & 2.77 & 8093.58 & 457.41 & 1139.97 & 23785.88 & $\mu \mathrm{m}$ \\
\hline Length & $l$ & 0 & 2384.38 & 141.91 & 331.11 & 7380.38 & $\mu \mathrm{m}$ \\
\hline Width & $w$ & 0 & 2172.35 & 84.22 & 3043.50 & 3480.47 & $\mu \mathrm{m}$ \\
\hline Feret min. & $F_{\min }$ & 0 & 1189.33 & 82.38 & 166.44 & 4285.38 & $\mu \mathrm{m}$ \\
\hline Feret max. & $F_{\max }$ & 0 & 2383.16 & 143.66 & 331.47 & 7470.69 & $\mu \mathrm{m}$ \\
\hline
\end{tabular}

Slightly more advantageous surface texture parameters values were measured on the machined surface in conditions of delivering a GF doped with powdered $\mathrm{MoS}_{2}(\mathrm{MQC}-\mathrm{M})$ as compared with values for the MQC-G option. These differences, in the case of the majority of the parameters, are not significant and are included in the range of between 10 and $15 \%$. The only exception in this respect is the $S t$ parameter value, which for the machined surface in conditions of delivering a GF with powdered graphite was $58 \%$ more than for the MQC-M option. It is worth noting that the value of the surface roughness height can be influenced even by a single peak or valley registered on the analyzed surface. This is extremely important in the case of a proper interpretation of the results of measurements obtained.

\subsection{Assessment of state of GWAS clogging of workpiece material}

Figures 5, 6, 7, 8 and 9 present SEM micrographs from the active surfaces of the examined grinding wheels after cylindrical grinding in Inconel ${ }^{\circledR}$ alloy 718 using five different varieties of the cooling conditions (MQC-M, MQC-G, MQC-E, MQC-W and FM-REF), acquired with a JSM5500LV scanning electron microscope.

Comparison of SEM micrographs of the examined GWAS (Figs. 5, 6, 7, 8 and 9) indicates that for the adopted grinding process parameters, both microcloggings of active abrasive grain apexes and (in some cases) vast cloggings of the intergranular spaces were intensively created. Moreover, this phenomenon occurred in the case of the examined grinding wheels with varied intensity. By far the most clogged active surface was that of the grinding wheel used for the grinding of Inconel ${ }^{\circledR}$ alloy 718 in the conditions of delivering non-doped demineralized water with the MQC method (option marked as MQC-W-Fig. 8). On the GWAS of grinding wheels operating in conditions of MQC cooling with the provision of GF doped with powdered $\mathrm{MoS}_{2}$ and graphite (Figs. 5 and 6, respectively), a qualitative analysis of the registered SEM micrographs showed a considerably smaller amount of clogging and which was observed only on active abrasive grain apexes.

As was revealed by the qualitative visual analysis of the SEM micrographs presenting fragments of the examined 


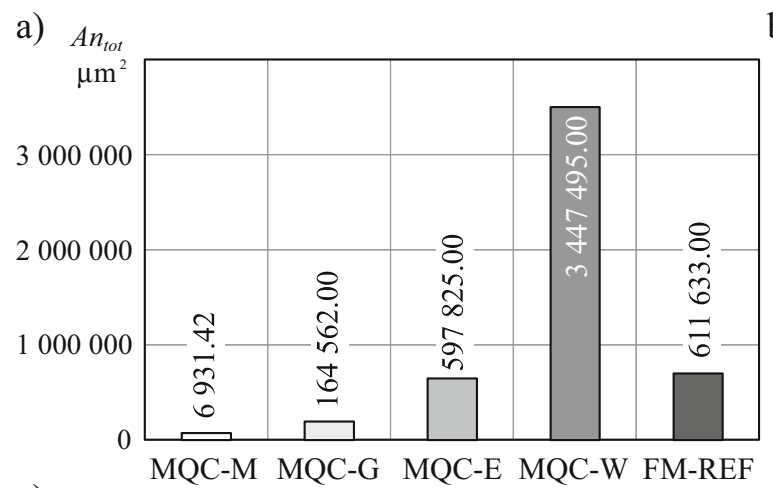

b) $\mathrm{An}$

c)

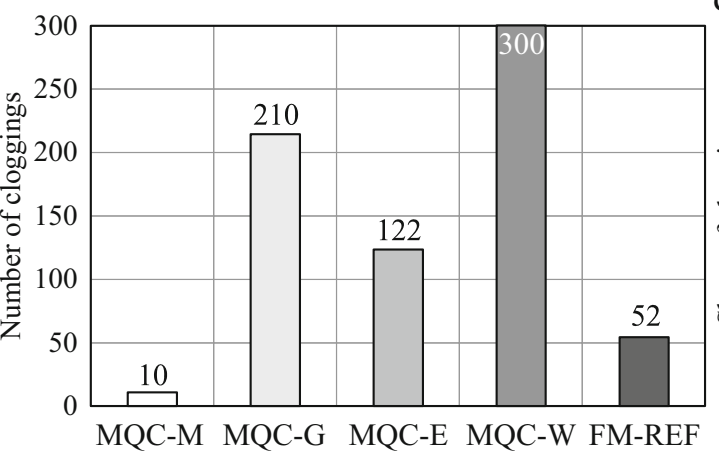

d)
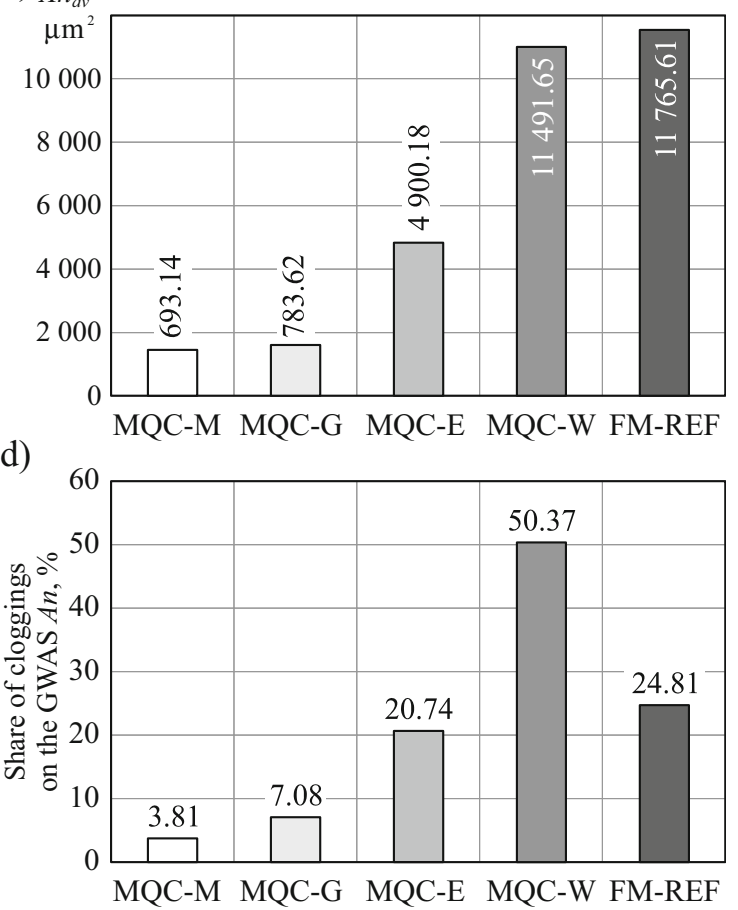

Fig. 15 Summary of numerical values of selected geometrical parameters of geometrical objects corresponding to the cloggings of the GWAS after the internal cylindrical grinding process of Inconel ${ }^{\mathbb{R}}$ alloy 718 during the image analysis carried out in Image-Pro ${ }^{\circledR}$ Plus 5.1 software for analyzed

grinding conditions. a Total area of cloggings. b Average area of cloggings. c Number of cloggings. d Percentage of the clogged area in analyzed image

GWAS acquired by the use of the scanning microscopy technique, there were significant differences concerning the level of their clogging with grinding products (Figs. $5,6,7,8$ and 9), leading to the conducting of more detailed quantitative analyses using image analysis and processing techniques being necessary. For this purpose SEM micrographs underwent binarization and then, on their basis, geometric parameters of the individualized objects were determined using a special Image-Pro ${ }^{\circledR}$ Plus 5.1 software. Figures 10,11, 12, 13 and 14 present results of the conducted quantitative analyses of the vast panoramas of the GWAS after grinding in five different conditions of cooling and grinding in the grinding zone of Inconel ${ }^{\circledR}$ alloy 718 . The next diagram (Fig. 15) presents charts of selected values of geometric parameters of areas singled out from SEM micrographs corresponding to GWAS clogging for each grinding zone cooling and lubrication variants.

Assessment of the quantitative analysis of SEM micrographs of the GWAS showed that the lowest total percentage of clogging in the analyzed areas occurred in the case of the grinding wheel operating in MQC-M conditions (3.81\%Fig. 15d). Moreover, in the case of the provision of a GF doped with powdered graphite, the clogging percentage was relatively low at $7.08 \%$. In both of the above-described cases, further proper use of the grinding wheels and continuation of the grinding process were possible.

In the case of grinding wheels operating in conditions of delivering emulsion into the grinding zone with the minimum (MQC-E-Fig. 12), or standard flow rate (FM-REFFig. 14), the clogging percentage exceeded $20 \%$ (20.74\% and $24.81 \%$, respectively-Fig. $15 \mathrm{~d}$ ). This is indicative of far greater adhesion of ductile machined material chips to the GWAS. What is also worth noting is the difference in the amount of gumming up in these two cases (Fig. 15c). On the analyzed active surface fragment of the grinding wheel operating in MQC-E conditions, 122 instances of clogging were observed, while in the case of FM-REF only 52, although there was one vast clogging which constituted almost $80 \%$ of the sum of surfaces of all singled out elements (Fig. 14). Such characteristics of the clogging surface distribution is particularly disadvantageous as vast clogging constitutes heat spots on the GWAS, which may even cause catastrophic damage of the grinding wheel with the ceramic bond (as it may snap under thermal stress). In both described cases (MQC-E and FM-REF), the percentage of clogging was deemed too high - which is indicative of the termination of the grinding wheel life and the necessity to carry out the procedure of dressing its active surface.

By far the greatest percentage of clogging on the GWAS (which was as much as 50.37\%) was registered in the case of delivering demineralized water with a minimum flow to the grinding zone (MQC-W-Fig. 15d). GF of this type is not 
GWAS AFTER THE INTERNAL CYLINDRICAL GRINDING OF INCONEL ${ }^{\oplus}$ ALLOY 718 | MQC-M Instrument type: (P)SEM | Model: Explorer | Producer: ASPEX Corp.

Acc. voltage: $15 \mathrm{kV}$ | Signal: BSED | WD: $10.0 \mathrm{~mm}$ | Spot size: 6.0 | Vacuum pressure: $50 \mathrm{~Pa}$
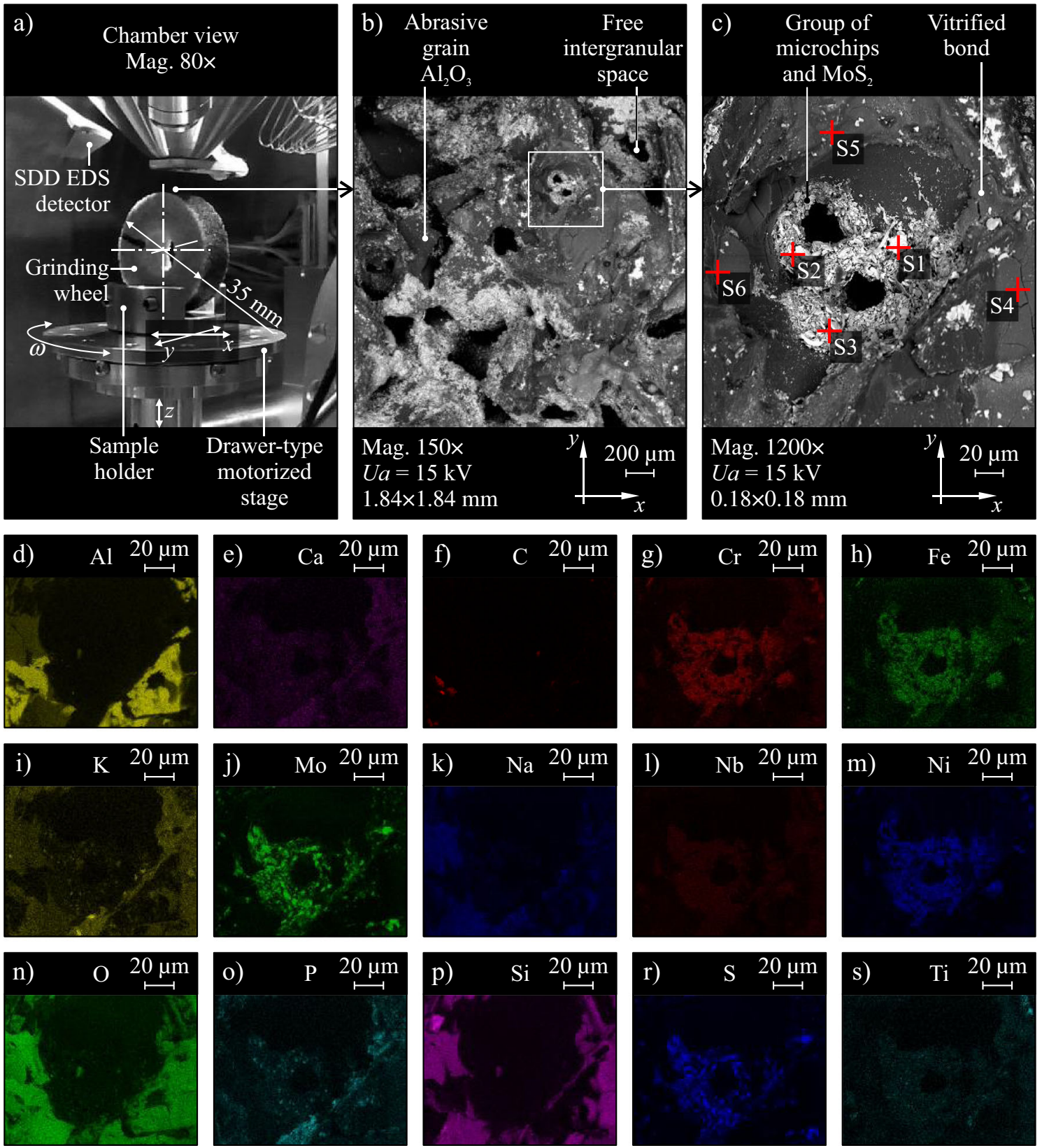

Fig. 16 Results of SEM/EDS analysis of the GWAS after grinding under MQC-M conditions. a View of vacuum chamber. b SEM micrograph. c SEM micrograph extracted from Fig. 17b with marked points of EDS analysis; d-s Microanalysis EDS — element maps on the GWAS

used in grinding processes and was included in the research just as a reference to GFs doped with powdered lubricating and antiadhesive substances in solid state. Comparing results of analyses for MQC-W (Fig. 13) and the results of MQC-M (Fig. 10) and MQC-G (Fig. 11) shows how advantageous doping GF with $\mathrm{MoS}_{2}$ and graphite is. The differences in the amount of the GWAS gumming up are almost 13 times higher for $\mathrm{MoS}_{2}$ and over seven times higher for graphite, as compared to the result obtained in MQC-W conditions (Fig. 15d).
The conducted quantitative analyses of SEM micrographs (Figs. 10, 11, 12, 13, 14 and 15) point to the considerable influence of doping GF in the form of demineralized water with powdered $\mathrm{MoS}_{2}$ and graphite (with a concentration of $30 \mathrm{~g} / \mathrm{dm}^{3}$ ), delivering it in an aerosol form of with a minimum flow rate $\left(Q_{G F}=1080 \mathrm{ml} / \mathrm{h}\right)$, on the intensity of clogging the GWAS with machined material chips. It can be therefore surmised that particles of solid grease effectively reached the area of contact between the BWAS and the 
GWAS AFTER THE INTERNAL CYLINDRICAL GRINDING OF INCONEL ${ }^{\oplus}$ ALLOY 718 | MQC-G Instrument type: (P)SEM | Model: Explorer | Producer: ASPEX Corp.

Acc. voltage: $15 \mathrm{kV}$ | Signal: BSED | WD: $11.2 \mathrm{~mm}$ | Spot size: 6.0 | Vacuum pressure: $50 \mathrm{~Pa}$
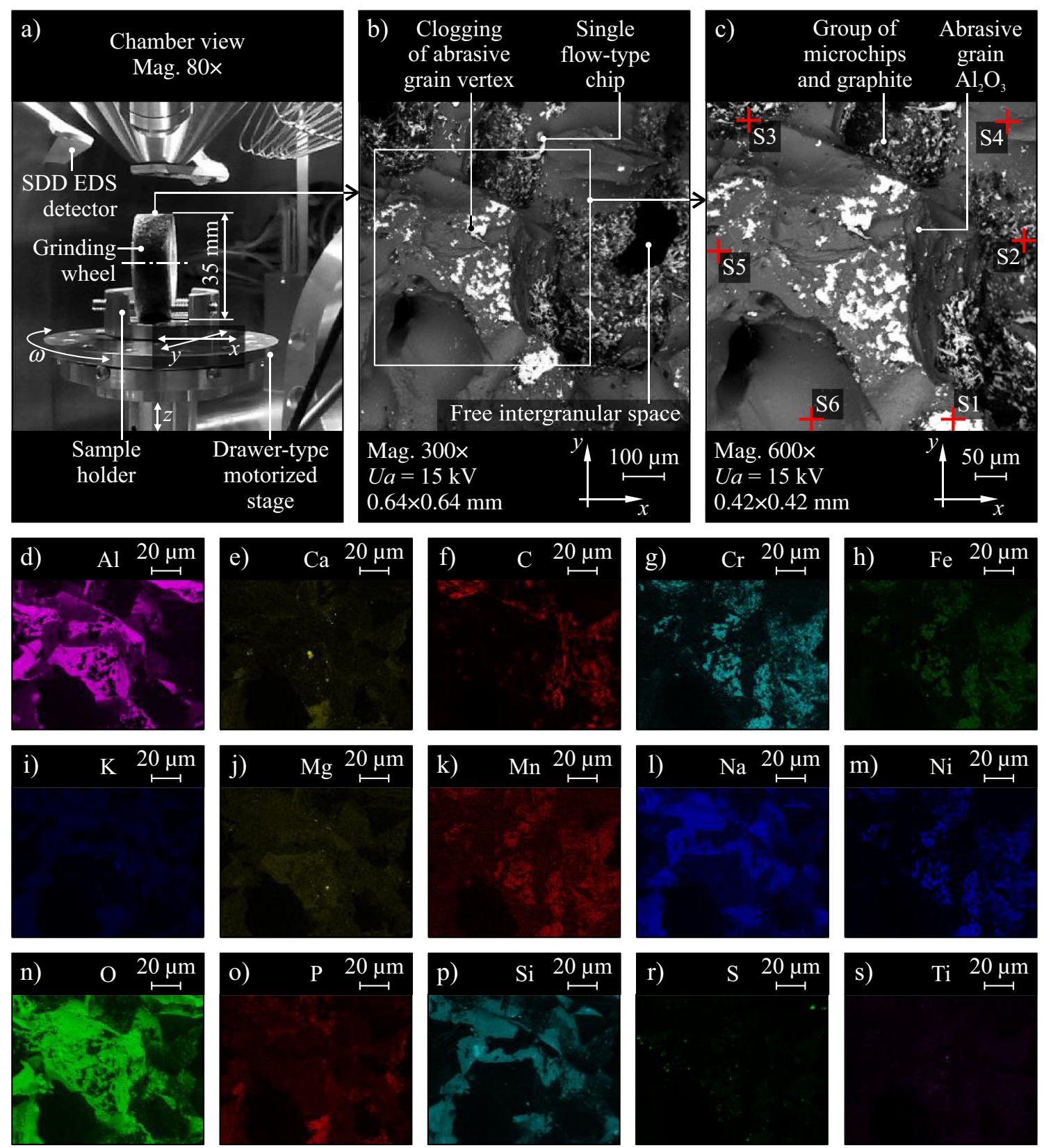

Fig. 17 Results of SEM/EDS analysis of the GWAS after grinding under MQC-G conditions. a View of vacuum chamber. b SEM micrograph. $\mathbf{c}$ SEM micrograph extracted from (b) with marked points of EDS analysis; $\mathbf{d}-\mathbf{s}$ microanalysis EDS - element maps on the GWAS

machined surface and actively influenced its tribological conditions. Additional confirmation of the presence of particles of powdered lubricating and antiadhesive substances in the area of direct contact of the active abrasive grains and the machined surface was possible due to the analysis of elemental composition on the GWAS after grinding in the form of surface maps and point EDS analyses, described in Section 3.4.

\subsection{EDS microanalyses of element composition on the GWAS after the grinding process}

For the purpose of detailed analysis of the GWAS and precise identification of objects located on it, apart from evaluating the amount of gumming up, EDS microanalyses of elemental composition and mapping their distribution on the GWAS were also carried out. An Explorer ${ }^{\mathrm{TM}}$ scanning electron 
GWAS AFTER THE INTERNAL CYLINDRICAL GRINDING OF INCONEL ${ }^{\oplus}$ ALLOY 718 | MQC-E Instrument type: (P)SEM | Model: Explorer | Producer: ASPEX Corp.

Acc. voltage: $15 \mathrm{kV}$ | Signal: BSED | WD: $8.6 \mathrm{~mm}$ | Spot size: 6.0 | Vacuum pressure: $50 \mathrm{~Pa}$
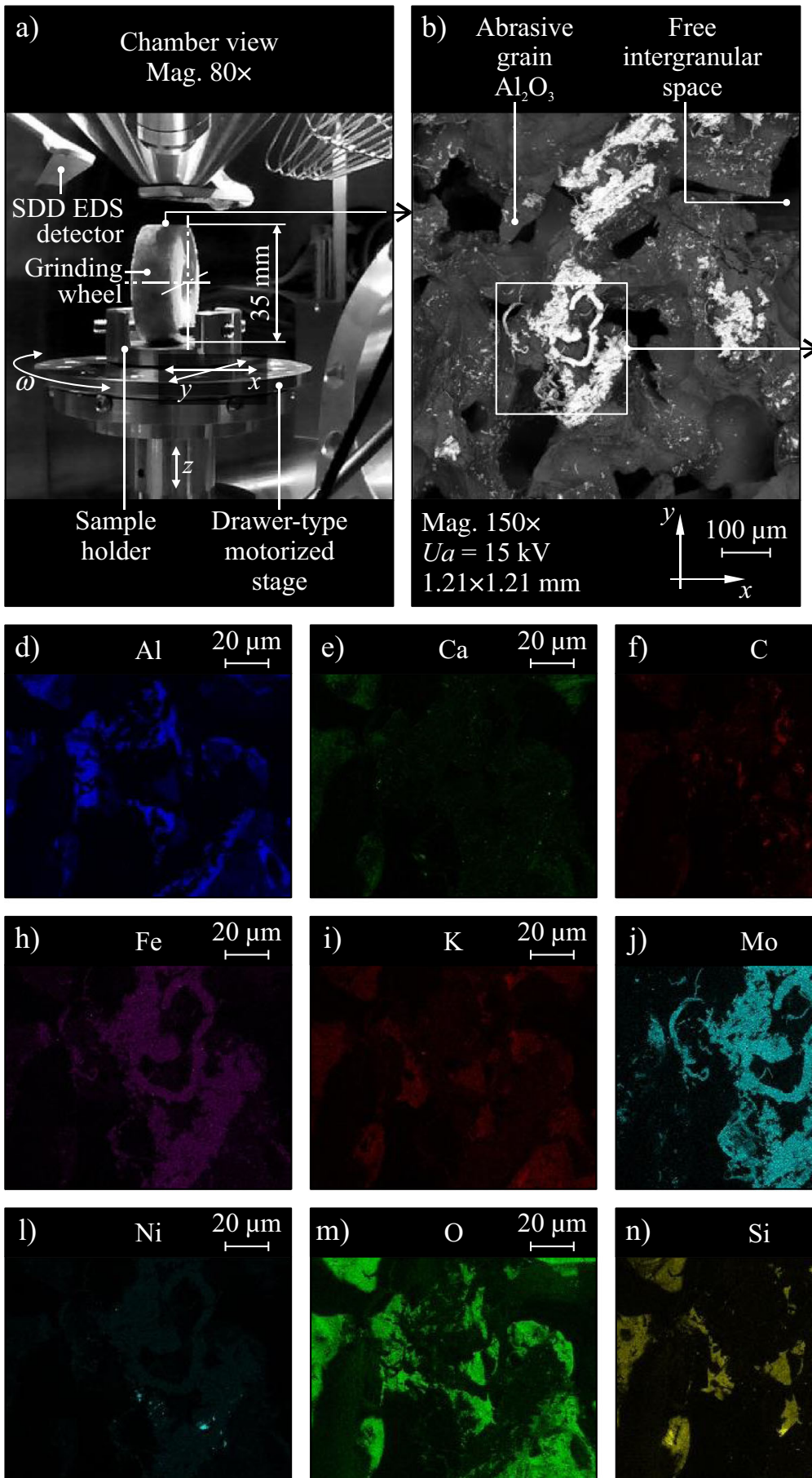
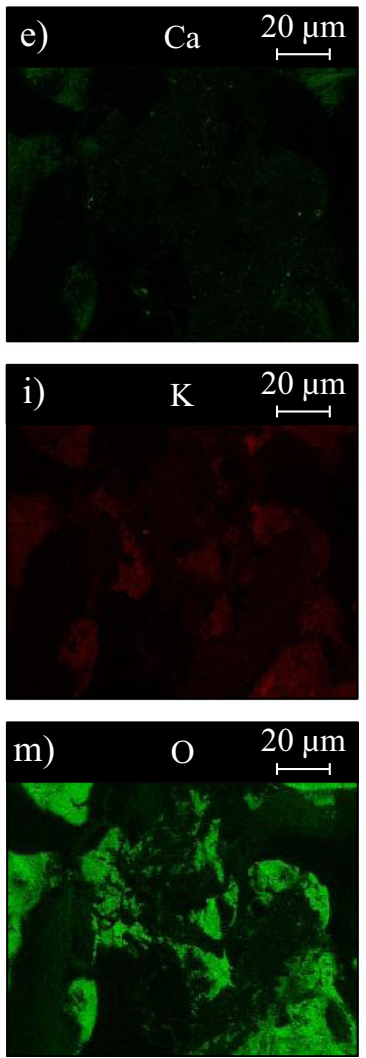
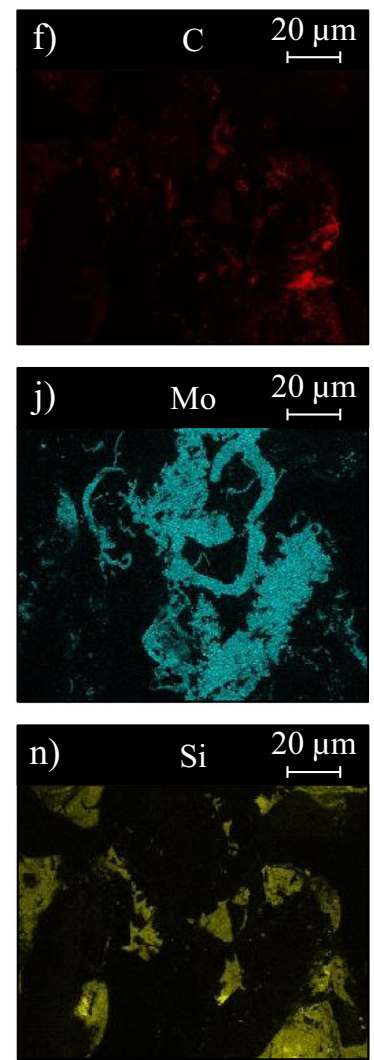
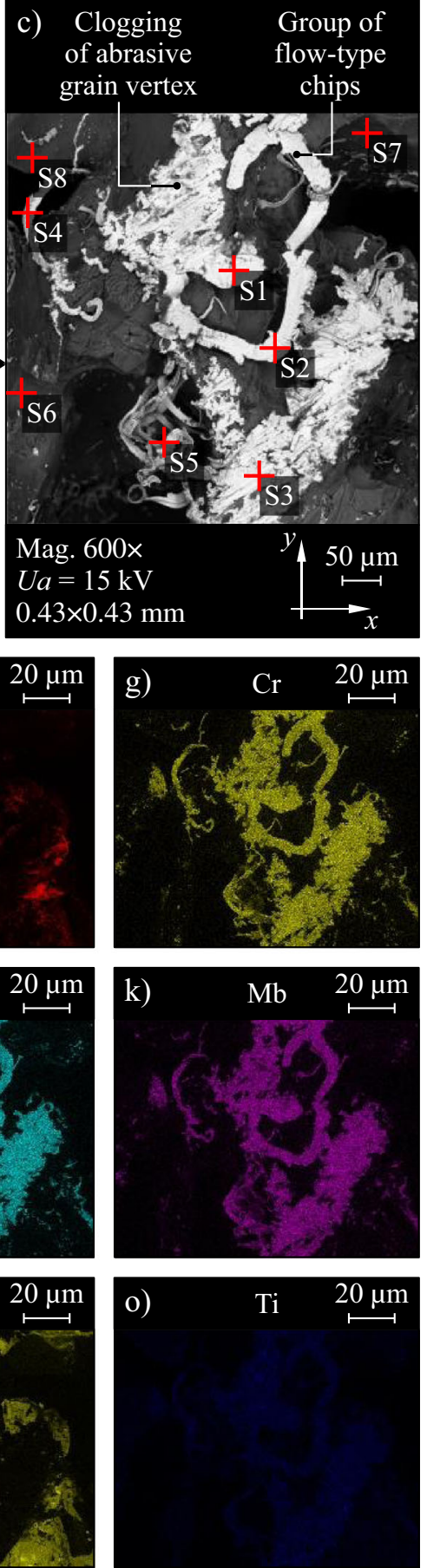

Fig. 18 Results of SEM/EDS analysis of the GWAS after grinding under MQC-E conditions. a View of vacuum chamber. b SEM micrograph. $\mathbf{c}$ SEM micrograph extracted from (b) with marked points of EDS analysis; d-o Microanalysis EDS-element maps on the GWAS

microscope with an SDD EDS OmegaMax ${ }^{\mathrm{TM}}$ detector were used to this end. These analyses were carried out for those grinding wheels that worked in conditions of delivering GF with the MQC method and for which the most advantageous results of grinding efficiency evaluation were observed, described in Section 3.1 (these were conditions abbreviated as MQC-M, MQC-G, and MQC-E). Figures 16, 17 and 18 present the results of EDS microanalysis in the form of maps showing the occurrence of elements on the GWAS, while Tables 3, 4 and 5 present EDS spectra, weight and atomic 
Table 3 Results of elemental composition EDS analysis for the GWAS after grinding in MQC-M conditions for marked points S1-S6 from Fig. 16c

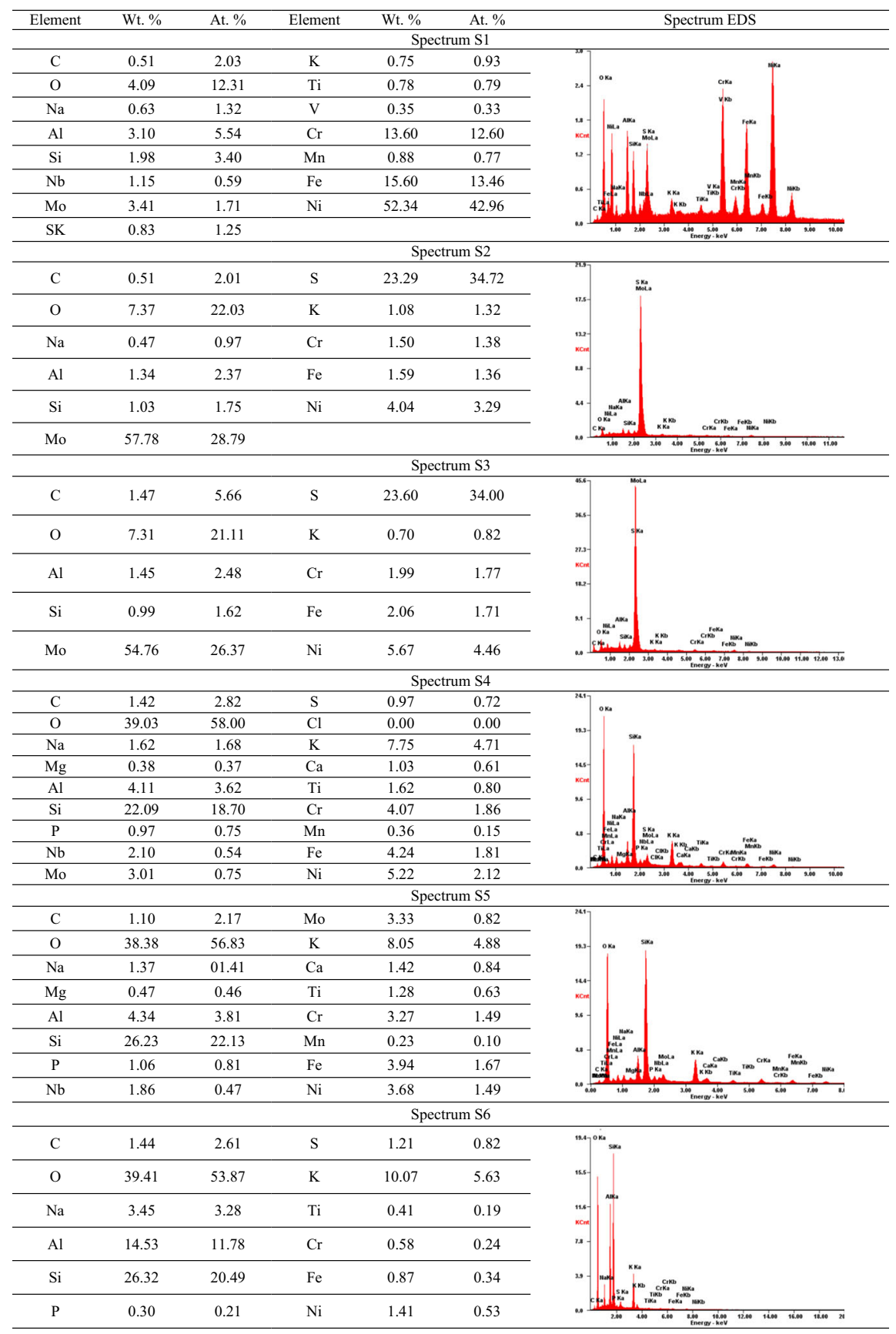

percentages of specific elements identified as a result of point EDS analyses on the grinding surfaces of the examined grinding wheels after grinding using three diverse GFs delivered with a minimum flow rate with the MQC method.

Microanalysis of elemental composition on the GWAS of the examined grinding wheels confirmed a considerable presence on the grinding wheel surface after work of elements that form part of the compounds with which the GFs were doped in the experimental studies. In the case of the grinding wheel which was used for grinding in conditions of delivering GF doped with $\mathrm{MoS}_{2}$ (MQC-M), both the elemental occurrence surface maps (Fig. 16), and EDS point analyses (Table 3) showed presence of Mo and $\mathrm{S}$ in groups of chips filling out the intergranular spaces visible in Fig. 16c. The result of surface mapping of Mo distribution is presented in Fig. 16j while S location on the analyzed GWAS fragment is presented in Fig. 16r. In reference to EDS point analyses, whose distribution is shown in Fig. 16c using symbols S1-S6, the greatest percentage of Mo and $\mathrm{S}$ was determined on the basis of S2 and S3 spectra 
Table 4 Results of elemental composition EDS analysis for the GWAS after grinding in MQC-G conditions for marked points S1-S6 from Fig. 17c

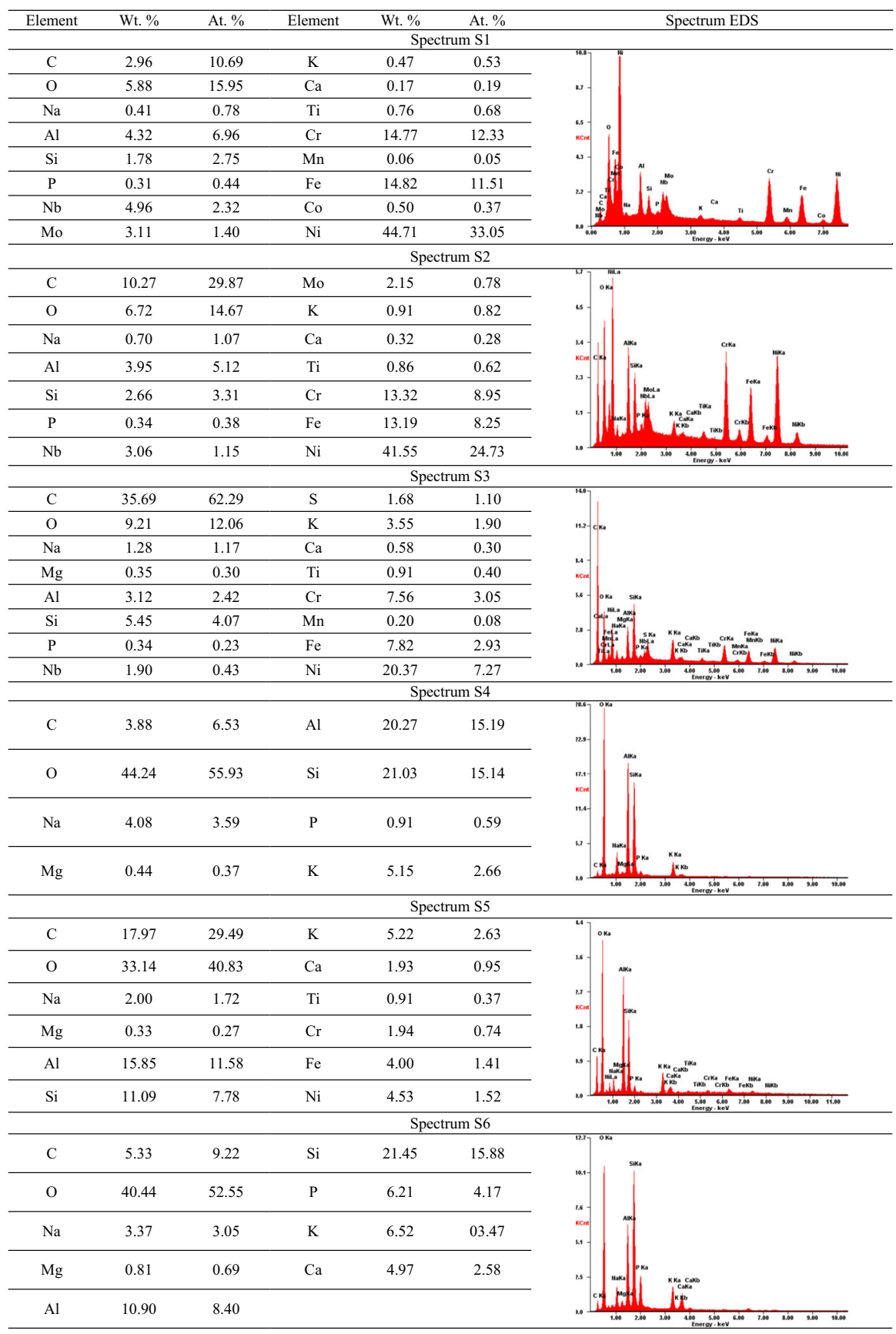

(Table 3). In spectra S2 and S3, the weight percentage of Mo was $57.78 \%$ and $54.76 \%$, respectively, which corresponded to the atomic percentage of $28.79 \%$ and $26.37 \%$, respectively. The weight percentage of S in these analyses was $23.29 \%$ for S2 and $23.60 \%$ for S3, which, in reference to the atomic percentage, was $34.72 \%$ for $\mathrm{S} 2$ and $34.00 \%$ for S3. In both of the above-described point EDS analyses (S2 and S3), the elements that were part of molybdenum disulfide $\left(\mathrm{MoS}_{2}\right)$ constituted the main part of the EDS spectrum (Table 3).
EDS microanalyses carried out on the GWAS after grinding in the conditions of delivering the GF doped with powdered graphite (MQC-G) showed a considerable presence of carbon in the intergranular spaces, among the microchips lying there (Fig. 17 and Table 4). The map of carbon distribution on the surface of the analyzed grinding wheel fragment is presented in Fig. 17f. Its analysis points to the greatest concentration of carbon in microchip clusters on the top and righthand side of the image. A point EDS analysis marked as S3 was carried out in the top part of the observed GWAS 
Table 5 Results of elemental composition EDS analysis for the GWAS after grinding in MQC-E conditions for marked points S1-S8 from Fig. 18c

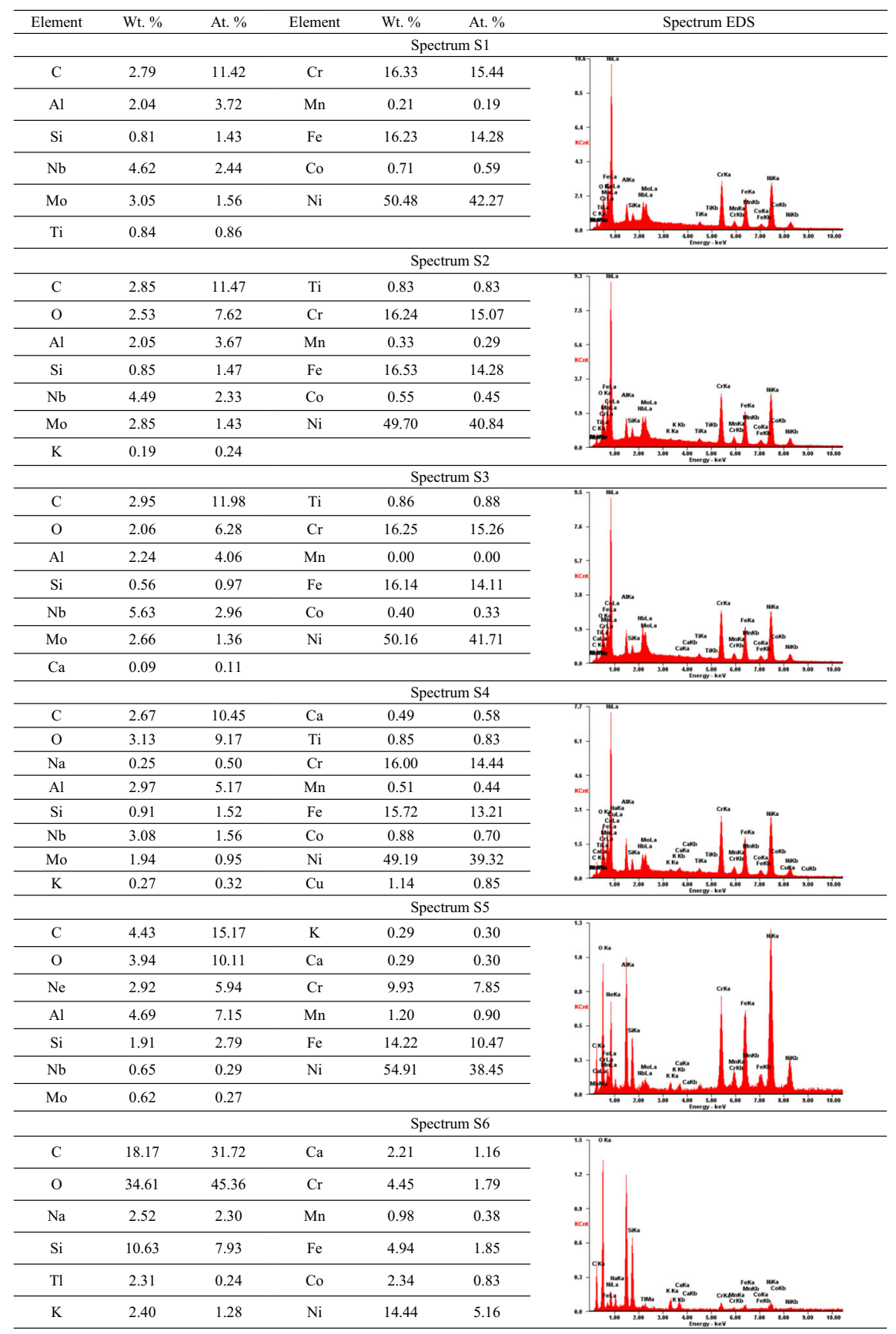

fragment (the analysis location is marked in Fig. 17c). This showed as much as $35.69 \%$ of a weight percentage of carbon, which corresponded to $62.29 \%$ of the atomic percentage in the designated EDS spectrum EDS (Table 4). This means that in S3 analysis carbon had the greatest percentage among the identified elements. Moreover, in the point analysis marked as $\mathrm{S} 2$ and $\mathrm{S} 5$, the amount of $\mathrm{C}$ was considerable and was $10.27 \%$ and $17.97 \%$ of the weight percentage and $29.87 \%$ and $29.49 \%$ of the atomic percentage, respectively.
Analyses of elemental composition on the GWAS after grinding in conditions of delivering emulsion with the MQC method (Fig. 18 and Table 5) did not show a considerable amount of any of the previously analyzed chemical elements (Mo, S, C). The surface distribution maps and point EDS analyses mainly refer to elements that form part of the machined material's composition (Inconel ${ }^{\circledR}$ alloy 718). Although it is an alloy of $\mathrm{Ni}, \mathrm{Co}$ and $\mathrm{Fe}$, it contains numerous additives (Nb, Ta, Mo, Ti, Al, Co, Mn, Si, Cu, P, S, C, B). Other 
detected elements can also be related to abrasive grains $\left(\mathrm{Al}_{2} \mathrm{O}_{3}\right)$, the ceramic bond (mainly glass), as well as compounds of the emulsion where Syntilo RHS oil constituted $5 \%$.

\section{Conclusions}

The experimental studies of internal cylindrical grinding conducted in five different conditions of cooling and lubricating the machining zone (Table 2) showed room for considerable improvement of tribological conditions of the analyzed process by doping GF with powdered lubricating and antiadhesive substances in a solid state (in the described research, this was molybdenum disulfide ( $\left.\mathrm{MoS}_{2}\right)$ and graphite). The obtained results of measurements and analyses allowed for drawing the following detailed conclusions.

1. The most favorable conditions of grinding wheel operation (the lowest mean grinding power $P$, the highest grinding index $G$ and advantageous surface roughness parameters values, e.g. $S a=0.210-0.236 \mu \mathrm{m}$ ) were obtained when delivering an aerosol of water slurry made from demineralized water doped with $\mathrm{MoS}_{2}$ and graphite with a concentration of $30 \mathrm{~g} / \mathrm{dm}^{3}$ with a minimum flow rate with the MQC method, as well as when delivering an aerosol of 5\% water slurry of Syntilo RHS oil with this method.

2. On active surfaces of grinding wheels operating in conditions of delivering the GF doped with $\mathrm{MoS}_{2}$ and graphite, the lowest surface clogging percentages $A n$ were registered, which were $3.81 \%$ and $7.08 \%$, respectively. These results were more favorable as compared with the results obtained in conditions of delivering non-doped GF (MQC-W), namely almost 13 times more for $\mathrm{MoS}_{2}$ and over seven times for graphite.

3. Analyses of the elemental composition on the GWAS, carried out in the form of surface maps and point EDS analyses, proved that the solid grease particles $\left(\mathrm{MoS}_{2}\right.$ and graphite) reached the area of contact of the GWAS and the machined surface effectively, actively (in a positive manner) influencing its tribological conditions.

4. The obtained grinding process results prove that the favorable influence of using GFs doped with powdered lubricating and antiadhesive substances in a solid state using the MQC method, known from the literature concerning flat surfaces grinding and external cylindrical grinding, can also be obtained for the internal cylindrical grinding process characterized by long path of contact between the GWAS and the machined surface that makes it more difficult for the GF to penetrate it and for the grinding products to be removed from it.
Acknowledgments The authors would like to thank the employees of Koszalin University of Technology for their help and support in selected steps of the experimental studies: Mr. Krzysztof Maciejewski from Laboratory of Metrology and Measurement Systems for carrying out the stylus measurements of the grinding wheel being used, Mr. Ryszard Gritzman from the Laboratory of Electron Microscopy and the Structural Research, Central Laboratory of the Faculty of Technology and Education for the acquisition of the SEM micrographs of analyzed workpiece, and Mr. Andrzej Nowicki from Laboratory Team I of the Faculty of Mechanical Engineering for his help during experimental studies of the grinding process.

\section{Compliance with ethical standards}

Conflict of interest The authors declare that they have no conflict of interest.

Open Access This article is distributed under the terms of the Creative Commons Attribution 4.0 International License (http:// creativecommons.org/licenses/by/4.0/), which permits unrestricted use, distribution, and reproduction in any medium, provided you give appropriate credit to the original author(s) and the source, provide a link to the Creative Commons license, and indicate if changes were made.

Publisher's Note Springer Nature remains neutral with regard to jurisdictional claims in published maps and institutional affiliations.

\section{References}

1. Żyłka $Ł$, Babiarz R (2017) Dressing process in the grinding of aerospace blade root. J Mech Sci Technol 31(9):4411-4417

2. Gdula M, Burek J, Zylka L, Plodzien M (2018) Five-axis milling of sculptured surfaces of the turbine blade. Aircr Eng Aerosp Tec 90(1):146-157

3. Grzesik W, Niesłony P, Habrat W, Sieniawski J, Laskowski P (2018) Investigation of tool wear in the turning of Inconel 718 superalloy in terms of process performance and productivity enhancement. Tribol Int 118:337-346

4. Qian N, Ding W, Zhu Y (2018) Comparative investigation on grindability of K4125 and Inconel718 nickel-based superalloys. Int J Adv Manuf Technol 97(5-8):1649-1661

5. Dai CW, Ding WF, Zhu YJ, Xu JH, Yu HW (2018) Grinding temperature and power consumption in high speed grinding of Inconel 718 nickel-based superalloy with a vitrified CBN wheel. Precis Eng 52:192-200

6. Liu G, Huang C, Zhu H, Liu Z, Liu Y, Li C (2017) The modified surface properties and fatigue life of Incoloy A286 face-milled at different cutting parameters. Mater Sci Eng A 704:1-9

7. Palanisamy A, Selvaraj T, Sivasankaran S (2018) Heat treatment effect on CNC turning of Incoloy $800 \mathrm{H}$ superalloy. Mater Manuf Process 33:1-8. https://doi.org/10.1080/10426914.2018.1424910.

8. Mandal A, Dixit AR, Das AK, Mandal N (2016) Modeling and optimization of machining nimonic C-263 superalloy using multicut strategy in WEDM. Mater Manuf Process 31(7):860-868

9. Unune DR, Barzani MM, Mohite SS, Mali HS (2018) Fuzzy logicbased model for predicting material removal rate and average surface roughness of machined Nimonic 80A using abrasive-mixed electro-discharge diamond surface grinding. Neural Comput \& Applic 29(9):647-662

10. Razak NH, Rahman MM, Kadirgama K (2014) Experimental study on surface integrity in end milling of hastelloy C-2000 superalloy. 
International Journal of Automotive and Mechanical Engineering 9: $1578-1587$

11. Jaladurgam NR, Kanjarla AK (2018) Hot deformation characteristics and microstructure evolution of Hastelloy C-276. Mater Sci Eng A 712:240-254

12. Xi X, Yu T, Ding W, Xu J (2018) Grinding of Ti2AlNb intermetallics using silicon carbide and alumina abrasive wheels: tool surface topology effect on grinding force and ground surface quality. Precis Eng 53:134-145

13. Liu C, Ding W, Yu T, Yang C (2018) Materials removal mechanism in high-speed grinding of particulate reinforced titanium matrix composites. Precis Eng 51:68-77

14. Rowe WB (2009) Principles of modern grinding technology. William Andrew, Burlington

15. Shen B, Shih AJ (2009) Minimum quantity lubrication (MQL) grinding using vitrified CBN wheels. Transactions of NAMRI/ SME 37:129-136

16. Wojcik R (2008) Application of new kinds of cooling media and supplying methods during surface grinding. Arch Mech Technol Mater 28(4):137-145

17. Dixit US, Sarma DK, Davim JP (2012) Environmentally friendly machining. Springer-Verlag, New York

18. Klocke F, Beck T (1998) Gut geschmiert statt schlecht gekühlt. Kühlschmierstoff reduzierung beim CBNHochgeschwindigkeitsschleifen. Werkstattstechnik 88(9-10):400404

19. Klocke F, Baus A, Beck T (2000) Coolant induced forces in CBN high speed grinding with shoe nozzles. CIRP Ann Manuf Technol 49(1):241-244

20. Webster J, Brinksmeier E, Heinzel C, Wittmann M, Thoens K (2002) Assessment of grinding fluid effectiveness in continuous-dress creep feed grinding. CIRP Ann Manuf Technol 51(1):235-240

21. Brinksmeier E, Brockhoff T, Walter A (1997) Minimum quantity lubrication in grinding. Proc. 2nd International Machining and Grinding Conference, SME. Michigan, USA, 8-11 September: 639-654

22. Brinksmeier E, Brockhoff T, Walter A (1997) Minimalmengenkuehlschmierung und Trochenbearbeitung beim Schleifen. Haerterein-Technische Mitteilungen. Proceedings for the 2nd International Machining \& Grinding Conference, September 8-11, 1997 Dearborn, MI, USA. 52:166-170

23. Brinksmeier E, Heinzel C, Wittmann M (1999) Friction, cooling and lubrication in grinding. CIRP Ann Manuf Technol 48(2):581598

24. Baines-Jones VA, Morgan MN, Allanson DR, Batako ADL (2005) Grinding fluid delivery system design - Nozzle optimisation. GERI Annual Research Symposium GARS2005, 22 June. Liverpool John Moores University, Liverpool, Great Britain

25. Karpiński T, Sieniawski J (2002) Ecological methods of cooling in grinding processes. Arch Civ Mech Eng 2(1-2):73-81

26. Nadolny K, Wojtewicz M, Sienicki W, Herman D (2015) An analysis of centrifugal MQL supply system potential in the internal cylindrical grinding process. Arch Civ Mech Eng 15(3):639-649

27. Tsai MY, Jian SX (2012) Development of a micro-graphite impregnated grinding wheel. Int J Mach Tool Manu 56:94-101

28. Alberts M, Kalaitzidou K, Melkote S (2009) An investigation of graphite nanoplatelets as lubricant in grinding. Int $\mathrm{J}$ Mach Tool Manu 49(12-13):966-970
29. Wojtewicz M (2017) Original methods of ceramic grinding wheels impregnation. J Mech Energy Eng 1(41):45-50

30. Nadolny K, Kapłonek W, Wojtewicz M, Sienicki W (2013) The assessment of sulfurization influence on cutting ability of the grinding wheels in internal cylindrical grinding of Titanium Grade $2 \circledR$. Indian J Eng Mater Sci 20(2):108-124

31. Kapłonek W, Nadolny K (2013) The diagnostics of abrasive tools after internal cylindrical grinding of hard-to-cut materials by means of a laser technique using imaging and analysis of scattered light. Arab J Sci Eng 38(4):953-970

32. Zhao B, Yu T, Ding W, Li X (2017) Effects of pore structure and distribution on strength of porous $\mathrm{Cu}-\mathrm{Sn}$-Ti alumina composites. Chin J Aeronaut 30(6):2004-2015

33. Saji S, Radhakrishnan V (2002) An investigation on surface grinding using graphite as lubricant. Int J Mach Tool Manu 42(6):733740

34. Mia M, Gupta MK, Singh G, Królczyk G, Pimenov DY (2018) An approach to cleaner production for machining hardened steel using different cooling-lubrication conditions. J Clean Prod 187:10691081

35. Weinert K, Inasaki I, Sutherland JW, Wakabayashi T (2004) Dry machining and minimum quantity lubrication. CIRP Ann Manuf Technol 53(2):511-537

36. Priarone PC, Robiglio M, Settineri L, Tebaldo V (2015) Effectiveness of minimalizing cutting fluid use when turning difficult-to-cut alloys. Procedia CIRP 29:341-346

37. Wang Y, Li C, Zhang Y, Li B, Yang M, Zhang X, Guo S, Liu G (2016) Experimental evaluation of the lubrication properties of the wheel/workpiece interface in MQL grinding with different nanofluids. Tribol Int 99:198-210

38. Zhang X, Li C, Zhang Y, Jia D, Li B, Wang Y, Yang M, Hou Y, Zhang X (2016) Performances of $\mathrm{Al}_{2} \mathrm{O}_{3} / \mathrm{SiC}$ hybrid nanofluids in minimum-quantity lubrication grinding. Int $\mathrm{J}$ Adv Manuf Technol 86(9-12):3427-3441

39. Zhang Y, Li C, Jia D, Li B, Wang Y, Yang M, Hou Y, Zhang X (2016) Experimental study on effect of nanoparticle concentration on the lubricating property of nanofluids for MQL grinding of Nibased alloy. J Mater Process Technol 232:100-115

40. Zhang Y, Li C, Jia D, Zhang D, Zhang X (2015) Experimental evaluation of the lubrication performance of $\mathrm{MoS}_{2} / \mathrm{CNT}$ nanofluid for minimal quantity lubrication in Ni-based alloy grinding. Int $\mathrm{J}$ Mach Tool Manu 99:19-33

41. Sinha MK, Madarkar R, Ghosh S, Rao PV (2017) Application of eco-friendly nanofluids during grinding of Inconel 718 through small quantity lubrication. J Clean Prod 141:1359-1375

42. Kapłonek W, Ungureanu M, Nadolny K, Sutowski P (2017) Stylus profilometry in surface roughness measurements of the vertical conical mixing unit used in a food industry. J Mech Eng 47(1):1-8

43. Kapłonek W, Nadolny K (2013) Assessment of the grinding wheel active surface condition using SEM and image analysis techniques. J Braz Soc Mech Sci Eng 35(3):207-215

44. Hryniewicz T, Rokosz K, Sandim HZ (2012) SEM/EDX and XPS studies of niobium after electropolishing. Appl Surf Sci 263:357361

45. Rokosz K, Hryniewicz T, Raaen S, Valiček J (2015) SEM/EDX, XPS, corrosion and surface roughness characterization of AISI 316L SS after electrochemical treatment in concentrated HNO3. Teh Vjesn 22:125-131 